\section{From Mesocates to Helicates: Structural, Magnetic and Chiro-Optical Studies on Nickel(II) Supramolecular Assemblies Derived from Tetradentate Schiff Bases}

\author{
Jffllia Mayans, ${ }^{[\mathrm{a}]}$ MercH Font-Bardia, ${ }^{[\mathrm{b}]}$ Lorenzo Di Bari, ${ }^{[\mathrm{c}]}$ Lorenzo Arrico, ${ }^{[\mathrm{c}]}$ Francesco Zinna ${ }^{[\mathrm{c}]}$ \\ Gennaro Pescitelli, ${ }^{[c]}$ and Albert Escuer ${ }^{*}[\mathrm{a}]$
}

[a] J. Mayans, Prof. A. Escuer Departament de Qu\&mica Inorg/nica i Org/nica, Seccij Inorg/nica and Institut de NanociHncia i Nanotecnologia (IN2UB), Universitat de Barcelona Mart\& i Franques 1-11, Barcelona 08028 (Spain) Homepage: www.ub.edu/inorgani/recerca/MagMol/magmol.htm

[b] Dr. M. Font-Bardia Departament de Mineralogia, Cristal-lografia i Dipksits Minerals and Unitat de Difraccij de R-X. Centre Cient\&fic i Tecnolkgic (CCiTUB) Universitat de Barcelona, Mart\& Franqu8s $\mathrm{s} / \mathrm{n}$, Barcelona 08028 (Spain)

[c] Prof. L. D. Bari, Dr. L. Arrico, Dr. F. Zinna, Dr. G. Pescitelli Dipartimento di Chimica e Ch\&mica Industriale, Universit/ di Pisa Via Moruzzi 13, 56124 Pisa (Italy)

Albert Escuer: albert.escuer@qi.ub.es 


\section{ABSTRACT:}

36 The systematic reactions of a family of tetradentate pyridyl/imine and quinolyl/imine racemic or

37 enantiopure Schiff bases with $\mathrm{Ni}(\mathrm{NO} 3) 2$ or $\mathrm{Ni}(\mathrm{ClO} 4) 2$ in the presence of sodium azide yielded, as a

38 function of the starting racemic, chiral or achiral base, a set of chiral, meso or achiral complexes. In all

39 cases, the compounds consist of two NiII cations linked by a double azido bridge in its end-on

40 coordination mode. All the dimers exhibit a mesocate supramolecular structure and one of them, the

41 unprecedented mix of helicate and mesocate in 2:1 ratio. The transition from mesocate to helicate

42 conformation has been reached by tuning the flexibility of the central spacers of the Schiff bases and the

43 size of the substituents. Electronic circular dichroism (ECD) studies have been performed for two pairs

44 of enantiomers and interpreted by means of DFT calculations. Susceptibility measurements show a

45 ferromagnetic coupling between the NiII cations mediated by the end-on azido bridges. 
49 Enantiopure polynuclear transition-metal complexes are becoming a subject of great interest in

50 coordination chemistry because they open a wide range of possibilities in the synthesis of new

51 materials,[1, 2] biochemistry,[3-6] drug design,[7] and catalysis.[8-12]

52 Control of chirality in supramolecular structures is a way to relate their properties and reactivity to their

53 structure in a predictable way. It allows the design of complexes with a controlled topology and with

54 specific physical properties such as electronic circular dichroism (ECD), circularly polarized

55 luminescence (CPL), non-linear optics, and magneto-chiral effects, etc.

56 Helicates and mesocates built around hexa- or tetra-coordinated metal cations, $[13,14]$ are among the

57 most studied supramolecular structures, because the self-assembly between the organic ligands and the

58 metal cations allows the parameters that direct the formation of supramolecular structures to be

59 elucidated; such factors include the electronic or steric preferences of the metal, the disposition of the

60 donor atoms in the ligand, or other factors such those postulated by M. Albrecht relating the preference

61 for one or other stereochemistry, for series of ligands with different spacers, with even or odd number of

62 C-atoms[15] of the chain or its flexibility.[16]

63 Ligands must be chosen carefully to prepare compounds of this kind because they must have the ability

64 to link different metal centers in spite of chelating a single cation. Bis-bidentate or bis -tridentate ditopic

65 ligands, in which the chelating fragments are linked by a flexible spacer, are extremely useful in this

66 field because they can afford complexes with a large variety of cations. In this sense, the first-row

67 transition metals have been specially studied, although structures with other transition metals or even

68 quadruple helicates with rare earths have also been reported.[17] Usually, all the coordination sites

69 around the metal are filled by the ligands, resulting in double helicates ([M2L2]n+) when the bis-

70 bidentate ligands react with cations that prefer a tetrahedral environment, or when the bis-tridentate

71 ligands react with cations that prefer a octahedral environment. When pyridyl/imine Schiff bases with an

72 ethylene spacer are employed as ligands, systematic characterization of [M2L2]n+ helicates have been

73 reported and, in both cases, the bidentate or tridentate units around the same cation have an ideal 908

74 angle between them. Furthermore, in both cases, the torsion angle subtended by the NCCN atoms of the

75 flexible spacer typically lies around 608, as shown in the analysis of the 30 reported structures with

76 pyridyl/imine ligands and tetrahedral CuI,[18-29] AgI,[24, 25, 30-35] or with bipyridyl/imine ligands

77 and octahedral ZnII, CuII or FeIII cations,[28, 36, 37] Scheme 1(a) and (b). Double NiII helicates with

78 the cations in octahedral environment and with two coordination sites occupied by one bidentate ligand

79 and employing the L2 Schiff base (Scheme 2), exhibit similar coordination sites for the N-donors and

$80 \mathrm{NCCN}$ torsion angles in the same range (Scheme 1c).[38] A special case is provided by double helicates

81 with general formula [M2(L)2X2]n+, (Scheme 1d). These systems, in which L corresponds to the bis-

82 bidentate pyridyl/imine Schiff bases L5 or L6 (Scheme 2) and X is a bridging ligand, are scarce and

83 have only been reported for CoII cations with $\mathrm{X}=\mathrm{oxo}$, or peroxo,[39] and for NiII cations with $\mathrm{X}=$ azido 
or cyanate.[40] In all cases, the [M2L2X2]n+ dimers exhibit a helicate arrangement and, as a consequence of the relative position of the pyridine ring, the corresponding NCCN torsion angle of the spacer becomes much larger - typically in the 80-908 range. An interesting characteristic of this kind of structure is that, in contrast to the LD mesocates, the helicity implies homochiral (LL or DD) stereochemistry around the metallic centers.

With the aim to characterize new [M2L2X2]n+ complexes and to study the relationship between helicates and mesocates in this kind of system that requires unusual NCCN torsion angles, we choose for this work a family of bis-bidentate Schiff bases (Scheme 2), containing four N-donor nitrogen atoms with a NCCN spacer able to promote the formation of discrete metal-ligand complexes. Three aspects have been taken into account to understand better the self-assembling of these structures. First, the tuning of the flexibility of the central saturated $\mathrm{C} @ \mathrm{C}$ bond of the spacer permits its influence in the final product to be studied: when the $\mathrm{C} @ \mathrm{C}$ bond presents a high degree of flexibility, the helicate structure should be allowed, whereas for a low degree of flexibility, only the mesocate should be achieved. Second, the steric effect of the aromatic substituents in the ligand was varied to check its influence in the final conformation, and, third, the effect of the chirality was considered as a driving force to form helicates against the former effects, because, as can be found in the literature, $[41,42]$ when an organic

100 ligand with a stereogenic center is used, it usually tends to yield chiral supramolecular helicate structures with the same configuration LL or DD for all the octahedral metal centers.

102 In this work we report the syntheses and characterization of a series of complexes with general formula 103 [Ni2L2(N3)2]A2 (A=NO3 @, ClO4@), obtained by the reaction of the corresponding NiA2 salt with 104 the selected L Schiff base in the presence of sodium azide, resulting in various kinds of compounds: the meso $1 \mathrm{M}$ and the chiral (1SS, 1RR) mesocate complexes with general formula [Ni2(L1)2(N3)2](NO3)2); the chiral mesocates [Ni2(L2)2(N3)2](NO3)2 (2SS, 2RR); several derivatives of L3 (3) with A=NO3 @ or ClO4 @ for which the structure was not fully determined; the mesocate [Ni2(R-L4)2(N3)2](ClO4)2 (4R); and the rare mixing in 1:2 ratio of mesocate and helicate conformations derived from the achiral ligand L7 with formula [Ni2(L7)2(N3)2](NO3)2 (7). All the synthesized complexes are dinuclear structures, as was expected, and they join several unusual features: the transition from mesocate to helicate has been tuned by changes in the ligands, showing in one case the unprecedented coexistence of mesocates and helicates in the same network; moreover, we achieved the synthesis of rare chiral mesocates due to the chirality of the ligands. In addition to the structural study, the systems have been characterized by electronic circular dichroism (ECD), DFT calculations and magnetic susceptibility measurements 


\section{Description of the structures}

The structures of the reported complexes are similar in their general trends. To avoid repetitive descriptions, the structure of $1 \mathrm{M}$ will be described in detail and only the more important features will be discussed for the remainder complexes. Intermolecular interactions and the supramolecular arrangement in the network will be discussed separately. meso-[Ni2(L1)2(N3)2](NO3)2 $2 \mathrm{MeOH}(1 \mathrm{M} \cdot 2 \mathrm{MeOH})$ : The molecular structure of $1 \mathrm{M}$ consists of a centrosymmetric cationic NiII 2 complex (Figure 1) and two NO3 @ counteranions. The main bond parameters are summarized in Table S1. Each bidentate pocket of the L1 ligand is coordinated to a different NiII cation acting as a bis-bidentate ligand. The NiII cations are octahedrally coordinated in a cis fashion by two bidentate fragments of L1 and two azido ligands in its end-on coordination mode. The main distortion of the octahedron is due to the low bite angle of the bidentate fragments that gives Nimine-Ni-Npy bond angles around 808. The Ni2N2 (Ni-(Nazido)2-Ni) central ring is planar, with similar distances to the azide bridging atoms, 2.104(1)-2.099(1) a, with a $\mathrm{Ni} \cdots \mathrm{Ni}$ distance of 3.0339(3) a. The azido ligands form an angle of 42.8(2)8 with the mean Ni2N2 plane. The hexane ring shows a chair conformation, with a $\mathrm{N}(2)-\mathrm{C}(7)-\mathrm{C}(12)-\mathrm{N}(3)$ torsion angle of 54.5(3)8. Each L1 ligand possesses two chiral C-atoms related by the inversion center placed in the dinuclear unit, and thus one possesses RR and the other SS chirality. In this complex, the L1 ligands are surrounding the NiII cations in a mesocate arrangement and consequently, the two NiII cations exhibit opposite L / D stereochemistry. The pyridyl rings linked to the same NiII cation form a 97.88 angle between mean planes. Intermolecular interactions between dinuclear units are weak $\mathrm{CH}^{\cdots} \mathrm{N}$ and $\mathrm{CH} \cdots \mathrm{O} \mathrm{H}$-bonds involving the nitrate counteranions, methanol solvent molecules and terminal $\mathrm{N}$-atoms of the azido ligands, and the only stronger $\mathrm{OH} \cdots \mathrm{OH}$-bonds present in the network are those between the methanol molecules and the nitrate counterions. [Ni2(RR-L1)2(N3)2](NO3)2 $2 \mathrm{MeOH}(1 \mathrm{RR} \cdot 2 \mathrm{MeOH})$ and [Ni2(SSL1)2(N3)2](NO3)2 $2 \mathrm{MeOH}$ (1SS $2 \mathrm{MeOH})$ : The structures of both enantiomers are practically identical and thus the following description is centered on 1RR, shown in Figure 2. Selected bond angles and distances for 1RR are listed in Table S2. As for the 1M complex described above, the dimers show a mesocate arrangement but in this case the dimers are not centrosymmetric.

Ni-Nazide-Ni bond angles are quasi identical (92.18/92.58), with an angle between the azides and the main Ni2N2 plane of 43.58. The octahedral coordination sphere of Ni(1) consists of two bonds to the

150 bridging azido ligands, two Nimine and two Npy donors with $\mathrm{Ni} @ \mathrm{~N}$ bond distances clearly larger for $151 \mathrm{Ni@Nimine} \mathrm{than} \mathrm{for} \mathrm{Ni@Npy.} \mathrm{The} \mathrm{situation} \mathrm{is} \mathrm{reversed} \mathrm{around} \mathrm{Ni2,} \mathrm{which} \mathrm{shows} \mathrm{Ni@Nimine} \mathrm{bond}$ 152 distances shorter than the Ni@Npy bond distances. The NCCN torsion angles of the central spacer (44.9(3)8/49.0(3)8) are lower than for 1M. As a consequence of these differences, the angle between 
pyridine rings linked to the same NiII cation is also asymmetric, with values of 92.4(2)8 for the rings linked to Ni1 and 103.8(2)8 for the pyridinic rings linked to Ni2. The intermolecular interactions are similar to those of $1 \mathrm{M}$.

[Ni2(RR-L2)2(N3)2](NO3)2 $3 \mathrm{MeOH}(2 \mathrm{RR} \cdot 3 \mathrm{MeOH})$ and [Ni2(SSL2)2(N3)2](NO3)2 $3 \mathrm{MeOH}$ $(2 \mathrm{SS} \cdot 3 \mathrm{MeOH})$ : The mesocate structures of $2 \mathrm{RR}$ and $2 \mathrm{SS}$ are similar in their general trends to the complexes $1 \mathrm{RR}$ and $1 \mathrm{SS}$ described above. In the case of $2 \mathrm{RR}$ and $2 \mathrm{SS}$, there are two similar but nonequivalent dimers in the unit cells, labelled A and B. Selected bond parameters are listed in Table S3 and a view of the A unit of 2RR is shown in Figure 3. The coordination spheres of $\mathrm{Ni}(1)$ and $\mathrm{Ni}(2)$ are also different, with the $\mathrm{Ni@Nimine} \mathrm{bond} \mathrm{distances} \mathrm{being} \mathrm{clearly} \mathrm{shorter} \mathrm{than} \mathrm{the} \mathrm{Ni@Npy} \mathrm{for} \mathrm{Ni}(1)$ (mean values 2.059 and 2.120 a, respectively), whereas the situation is the opposite for $\mathrm{Ni}(2)$, with $\mathrm{Ni@Nimine} \mathrm{mean} \mathrm{bond} \mathrm{distance} \mathrm{of} 2.179$ a and Ni@Npy of 2.124 a. The NCCN torsion angles are 48.1(7)8/47.6(6)8 for mol ecule 2RR-A and 52.8(6)8/51.3(6)8 for molecule 2RR-B, and the angles between the quinolyl mean planes linked to the same NiII cations are clearly different, with values of 110.5(2)8/106.3(2)8 for the A unit and 94.2(2)8/91.0(2)8 for the B unit and Ni1/ Ni2, respectively. [Ni2(R-L4)2(N3)2](ClO4)2 $\times \mathrm{xMeOH}(4 \mathrm{R} \cdot \mathrm{xMeOH})$ : A labeled plot of $4 \mathrm{R}$ is shown in Figure 4 and the main bond parameters are listed in Table S4. The molecular structure of the mesocate complex 4R is very similar to the complexes $2 \mathrm{RR} / \mathrm{SS}$ described above, with two independent dimers (labeled as A or B) in the unit cell, similar Ni-N-Ni bond angles and the sameNi@Nimine/Ni@Nqx bond distances relationship for Ni1 and Ni2. The main differences lie in the lower NCCN torsion bonds, with values of 48.3(9)8/39.3(9)8 for the A unit and 39.1(7)8/33.9(8)8 for the B dimer. The dihedral angle between mean quinolyl planes linked to the same NiII cation is similar in both dimers, ranging between 104.9(3)8 and 109.9(2)8.

[Ni2(L7)2(N3)2](NO3)2 2 $\mathrm{H} 2 \mathrm{O}, 2 \mathrm{MeOH}$ (7): The exceptional structure of compound 7 consists of two non-equivalent dimers, labeled $\mathrm{A}$ and $\mathrm{B}$, one of them with mesocate centrosymmetric arrangement (7B) and the other with helicate noncentrosymmetric structure (7A). The presence of inversion centers in the network generates two molecules with opposite helicity 7A-D and 7A-L; thus, there are three different dimers in the achiral network. The main bond parameters are listed in Table S5 and a view of the mesocate and one of the helicates is shown in Figure 5. The mesocate unit 7B is similar to the previously described systems with the same conformation, showing larger $\mathrm{Ni} @ \mathrm{Nqx}$ bond distances than the Ni@Nimine ones, a NCCN torsion of the central spacer of 50.1(7)8, and a dihedral angle between quinolyl mean planes of 94.0(1)8.

The 7A helicate molecule shows Ni@Nqx are greater than Ni@ Nimine bond distances for both Ni1 and $\mathrm{Ni} 2$ environments, with similar dihedral angles between the quinolyl planes (110.8(2)8/108.0(2)8). The key difference with the precedent mesocates lies, as expected, in the larger NCCN torsion angles, which take values of 83.7(6)8 and 81.2(5)8. Ni-N-Ni bond angles are 99.3(2)8 and 100.5(2)8. [Ni2(L3)2(N3)2]A2·solvent (A=NO3@, ClO4@) (3): Diffraction data were collected for multiple crystals of the complexes derived from rac-L3 or chiral-L3 ligand and nitrate or perchlorate 
counteranions but trials to solve the structure were unsuccessful. The complexes crystallize in nice polyhedral crystals that diffract correctly but fail in the refinement process. The obtained molecules show images in which both conformations seem to overlap and with disordered azido ligands with large deviation from linearity (Figure S1). In light of the partial structural results, the presence of both mesocate and helicate conformations seems to be consistent, although caution must be assumed.

\section{Network supramolecular arrangement}

The most conventional noncovalent interaction forces that determine the network supramolecular arrangement for systems containing aromatic rings are typically p-p stacking. In addition and equally important, electron-deficient aromatic rings such as those containing coordinated N-donors, can promote other interactions that were found to be determinant in biological systems, but rarely studied in cluster chemistry, such as anionp or lone pair-p interactions.[43] The weaker $\mathrm{CH}^{\cdots} \mathrm{p}$ interaction has also been revealed as a determinant in the crystal packing.[ 44] Complexes 1M, 1RR, and 1SS, containing pyridyl rings, do not show remarkable interdimer interactions in the network. In contrast, when the quinolyl aromatic fragment is present in the structures, it promotes intermolecular interactions, which determines the spatial arrangement of the molecules. Intermolecular interactions in complexes $2 \mathrm{RR}$ and 2SS are dominated by the p-p stacking of the aromatic rings of the quinolyl groups, which show a distance between the centroids of the phenyl fragments of $3.645 \mathrm{a}$. In addition, there are two $\mathrm{CH} \cdots \mathrm{p}$ interactions between one of the $\mathrm{H}$-atoms of the phenyl ring and one phenyl fragment of the neighbor molecule (Hcentroid distances of 2.565 and 3.152 a). As a consequence of these interactions, the molecules are ordered forming parallel chains where the $\mathrm{A}$ and $\mathrm{B}$ nonequivalent dimers present in the unit cell are arranged in an ABABA alternating sequence along the chains (Figure 6).

As in the previous case, the structure of $4 \mathrm{R}$ contains two nonequivalent dimers (named A and B). The network consists of layers of parallel chains of B molecules and noninteracting A dimers between the layers, which are surrounded by perchlorate anions and solvent molecules, giving a complex set of weak $\mathrm{C} @ \mathrm{H} \cdots \mathrm{O}$ H-bonds. The interaction that generates the B chains is the p-p stacking of the quinolyl fragments, with interplanar distance of around $3.3 \mathrm{a}$, and a distance between the centroids of the phenyl and the pyridyl fragments of $3.542 \mathrm{a}$. In this case, one O-atom of the perchlorate counteranion gives an anion-p ring interaction with a distance between the Odonor and the centroid of the pyridyl ring of 2.900 a. This interaction avoids the possibility of $\mathrm{CH} \cdots$ p interactions (Figure 7).

The structure of complex 7 contains a centrosymmetric mesocate and two helicates with opposite $\mathrm{D} / \mathrm{L}$ helicity. The intermolecular interactions provide an exceptional example of chiral recognition in an achiral network. The mesocates form layers of parallel chains of dimers linked by the same kind of intermolecular interactions as have been described above for compounds 2RR/2SS (Figure 6); namely, p-p stacking of the aromatic rings of the quinolyl groups, with a distance of 3.424 a between main 
planes and of 3.715 a between centroids, plus symmetric $\mathrm{CH}^{\cdots} \mathrm{p}$ ring interactions (H-centroid of the phenyl ring distance of $2.866 \mathrm{a}$ ). Between the mesocate planes, there are layers of helicates formed by homochiral parallel chains of LL and DD dimers related by inversion centers (Figure 8). In these helical chains the intermolecular interactions are dominated by double $\mathrm{CH} \cdots p$ ring interactions with $\mathrm{H}$ ring(pyridyl) distance to centroids of 2.643 a and H-ring(phenyl) of $2.901 \mathrm{a}$. The p-p stacking is less effective than for the mesocates because the aromatic rings are not parallel.

\section{Electronic and vibrational circular dichroism}

Vibrational circular dichroism (VCD) of 1RR/SS and 2RR/SS in the solid state (KCl pellets) was preliminarily investigated with the aim of identifying metal-induced VCD enhancements.[45, 46] However, no VCD enhancement was observed, probably because there are no d-d transitions of suitable energy to effectively mix with the vibrational transitions.[47] Under these conditions, the VCD signals are too weak with respect to the artifacts due to linear anisotropies in the solid state; therefore, it was not

possible to obtain reliable VCD spectra.

244 Solid-state ECD spectra were measured as $\mathrm{KCl}$ pellets for 1RR and 1SS in the 350-900 $\mathrm{nm}$ region. They display several bands with non-negligible rotational strength (Figure 9, top). These bands have an expected main d-d character; however, their nature is in fact more complex (see the computational analysis section). The spectra measured on the two enantiomers are perfect mirror images, ensuring that there are no significant contributions from linear dichroism/linear birefringence.[48] In this case, it was not possible to obtain a disc of sufficient quality to penetrate below $350 \mathrm{~nm}$. Solution spectra measured in acetonitrile display several relatively intense bands also in the $200-350 \mathrm{~nm}$ region, where the character of the transitions is mainly, although not exclusively, ligand centered (Figure 9, bottom). For complexes 2RR/SS, it was possible to obtain $\mathrm{KCl}$ discs suitable to penetrate down to $250 \mathrm{~nm}$ (Figure 10, top). We note that the intensity ratio between long-wavelength and short-wavelength transitions is lower than in the 1RR/SS case. This fact is appreciable both in the solid state and in the solution spectra (Figure 10, bottom), and is related to the stronger electronic transitions of the quinoline chromophores with respect to the pyridine ones.

257 It is interesting to compare the solution and the solid-state ECD spectra. It is apparent from Figure 11 that the two pairs of spectra are almost perfectly superimposable in the longer wavelength region, 400 $900 \mathrm{~nm}$, whereas shorter wavelength transitions (above $350 \mathrm{~nm}$ ) maintain the same shape and sign in the two media but with different relative intensity; a higher intensity is observed in solution than in the solid state. This indicates that, although small ligand rearrangements can occur upon solvation, Ni-centered transitions are not significantly affected. Furthermore, intermolecular interactions that may occur in the microcrystalline solid-state samples are more effective for ligand-centered transitions, because of their stronger electric-dipole allowed character.[49] 
Time-dependent density functional theory (TDDFT) was employed to simulate the ECD spectra of compounds 1SS.[50] It must be stressed that excited-state calculations of open-shell Ni complexes with high spin are very demanding.[51,52] In the current case, the situation is further complicated by the presence of four chromophores, each with several transitions. In fact, a very high number of transitions needed to be considered; however, TDDFT calculations are intrinsically less accurate for high-lying states.[53] As a consequence, only a portion of the ECD/UV spectra may be investigated (above ca. 300 $\mathrm{nm}$ ), and our analysis is not expected to perfectly reproduce the experimental spectra. In Figure 12 we show the absorption and CD spectra calculated for 1SS at CAM-B3LYP/LanL2DZ level, which gave the best results (see the Computational Section). The input structure was obtained by reoptimizing the X-ray geometry with DFT at the B3LYP/6-31G(d) level of theory; an input structure with +2 charge (devoid of counteranions) and quintet spin state was used in all calculations. Many distinct transitions contribute to the observed absorption and ECD bands; moreover, orbital and population analysis reveal that each transition is due to several different single excitations. This renders a full spectrum assignment impossible in terms of easily identified transitions, especially because there is no clear separation between metal- and ligand-centered transitions, and metal-centered transitions occur deeply in the UV region of the spectrum. We have already observed this behaviour before for high-spin Ni complexes with chromophoric ligands.[52] As an example, we summarize the assignment of the two transitions contributing most to the two observed negative ECD bands observed around 650 and $480 \mathrm{~nm}$ of 1SS, calculated at 482 (transition labeled \#7 in Figure 12) and $370 \mathrm{~nm}$ (\#17), respectively. The former band is a mixing of several excitations, the dominant ones being those from the $\mathrm{pC}=\mathrm{N}$, ppy $\mathrm{C}=\mathrm{N}$, and $\mathrm{dxz}$ orbitals to a mixed $\mathrm{pN} 3 *+$ dyz orbital (the $\mathrm{z}$ axis is along the Ni-Ni direction). The latter band is also a mixing of many excitations, the dominant ones being those from a mixed ppy$\mathrm{C}=\mathrm{N}+\mathrm{dy} 2+\mathrm{z} 2$ orbital to the two mixed ppy*/dyz and ppy*/dx2 orbitals. One clear result from the calculations is that the apparent baseline drift above $800 \mathrm{~nm}$ in the ECD spectra is due to a real ECD

\section{Helicate versus mesocate conformation}

293

Helicates and mesocates are supramolecular structures formed by the self-assembly of metallic centers and bridging ligands, as has been described previously. Double helicates with M2L2 and triple helicates with M2L3 stoichiometry are formed by bisbidentate ligands bound to two tetrahedral or octahedral metal centers, respectively. In the latter case, this arrangement generates a homochiral (LL or DD) helical structure. For a dinuclear double helix built with these types of ligand, it is postulated that the spacer must have an adequate size, enough rigidity to sterically favor the coordination of the two bidentate fragments to different cations, and it also needs enough flexibility to permit the wrap around the $\mathrm{M} \cdots \mathrm{M}$ axis of the molecule. 
For cations showing octahedral coordination, the triple M2L3 helicates with C3 symmetry are the most common structures (Figure 13, left). In this case, the main axis of the molecule is placed on the center of opposite triangular faces of the octahedral and NCCN torsions around 608 are enough to satisfy the helicate requirements. A large number of M2L2 (M=tetrahedral CuI, CuII, AgI) helicates have been reported for ligands with a two-C spacer like those employed in the present work, with NCCN torsion angles also around 608.[18-35] In contrast, for the less common ML2 X2 double helicates with monoatomic or small double $\mathrm{M}-\mathrm{X}-\mathrm{M}$ bridges, the symmetry is reduced to $\mathrm{C} 2$, with the main molecular axis along the center of opposite edges of the octahedra (Figure 13, right). This arrangement requires larger NCCN torsion angles closer to 908 , as has been experimentally proved for [Ni2(L5)2(m11-N3)2](ClO4)2 (NCCN=78(1)8/80.0(9)8), [Ni2(L6)2(m11-N3)2](ClO4)2 $(\mathrm{NCCN}=92.8(4) 8 / 93.4(4) 8),[\mathrm{Ni2}(\mathrm{L} 6) 2(\mathrm{~m} 11-\mathrm{NCO}) 2](\mathrm{ClO} 4) 2(\mathrm{NCCN}=93.8(4) 8 / 94.0(4) 8),[38]$ [Co2(L5)2(m-O)(m-(O2)]A2 (A=BF4 @, NCCN=80.2(5)8/81.1(5)8; A=ClO4@, $\mathrm{NCCN}=80.5(3) 8 / 81.1(3) 8)$. [39, 40] In light of these data, our aim was to explore the reactivity of ligands with different flexibility or aromatic donors with different size in order to tune the selective syntheses of homochiral (LL or DD) helicate or heterochiral (LD) mesocate structures for the ML2X2 case and to obtain experimental evidence of the factors that determine the formation of one or another type of structure.

Steric requirements were centered on the flexibility of the $\mathrm{C} @ \mathrm{C}$ central spacer and size of the aromatic rings. Our starting point was the analysis of the experimentally reported torsion angles on the $\mathrm{C} @ \mathrm{C}=\mathrm{NCCN}=\mathrm{C} @ \mathrm{C}$ fragment belonging to any kind of Schiff bases for the spacers cyclohexane (690 structures), methylethyl (72 structures) and ethyl (2865 structures). From these data emerge two interesting features: first, the preferred NCCN torsion angle of the spacer lies around 40-508, with practically $50 \%$ of the structures falling in this range and, second, the ethyl fragment appears to be more flexible than the cyclohexane or methylethyl fragments, showing several structures with NCCN torsion angles larger than 808 (Figure S2). The same analysis for the pyridyl ligands L1 (46 structures), L3 (9 structures), and L5 (95 structures) reflect the same general trends; that is to say, the same preferred torsion angle and the larger flexibility of the ethyl fragment. For L1 in all cases the NCCN torsion is comprised between 39.58 and 73.88 with one unique case reaching 788; for L3 the torsion lies in the very short range of 45.2-66.68; whereas, for L5 it spans all values between 08 and 93.88 (Figure S3). There are a few reported complexes for the quinolyl ligands L2 (12 structures), L4 (zero structures), and L7 (3 structures), and although the available information is scarce, it indicates that the NCCN torsion for L1 is limited to a short range of angles comprised between 53-668. From this structural analysis, the larger flexibility of the ligand for unsubstituted spacers and smaller ring size can be inferred. As could be expected, the most rigid ligands are those containing the cyclohexane ring, which prevents extreme torsions; effectively, L1 and L2 are not flexible enough in the spacer to produce the helicate. As experimental confirmation, the mesocate arrangement was obtained for $1 \mathrm{M}, 1 \mathrm{SS}, 1 \mathrm{RR}, 2 \mathrm{SS}$, and $2 \mathrm{RR}$. 
L3 and L4 should, in principle, be slightly more flexible in the spacer than their analogous L1 and L2 with cyclohexane spacer, and, according to the previous analysis, L3 should be more flexible than L4. Then, is not surprising that the mesocate arrangement is the preferred form for $4 \mathrm{R}$, whereas both helicate and mesocate forms seem to be equally preferred for L3. In the same way and following the same tendencies, both forms seem to be equally favored for the quinolyl ligand L7 with an ethyl spacer, whereas the helicate is exclusively formed for the previously reported[38-40] most flexible ligands L5 and L6.

Thus, we can conclude that the combination of the flexibility of the spacer and the difference in the volume of the aromatic chromophore, promotes a well-established effect on the resulting supramolecular arrangement, showing a perfect transition from mesocate to helicate arrangement for the ML2(m-X)2 case. The combination of both effects can be graphically seen in Scheme 3.

On the other hand, the transfer of chirality from the chiral center of the ligands to the cations or the whole supramolecular assembly is a common fact and it is widely accepted that chiral molecules (ligands in the particular case of coordination chemistry) generate chiral supramolecular systems. This interesting feature, where the ligand transfers its chirality to the metal centers, has been called predetermined chirality, $[9,41,42]$ with the LL or DD configurations of the stereogenic metal centers being completely controlled by the chiral configuration of the ligands.[54] In our case, this assumption means that the employment of enantiomerically pure ligands should lead to the formation of homochiral helicates with homochirality at the level of the metal centers and helicity of the molecules. However, in contrast with these rules, for compounds $1 \mathrm{SS}, 1 \mathrm{RR}, 2 \mathrm{SS}, 2 \mathrm{RR}$, and 4R for which chiral ligands were employed, the mesocate configuration was obtained. These results highlight the possibility that even when the ligand has a stereodefined chiral center and the bridging mode of the ligand allows for conformational chirality, the final structure cannot present an overall chirality by rational control of the properties of the ligand. On the other hand, the final mesocates retain the chirality only through the presence of asymmetric $\mathrm{C}$-atoms of the ligands, resulting in the extremely unusual chiral mesocates.

\section{Susceptibility studies}

The magnetic response for double azido bridges with Ni-N-Ni bond angles has been well established, giving strong ferromagnetic interaction for bond angles around 1008.[55] To check the magnetic properties of the reported compounds, susceptibility measurements were performed for the series of compounds 1 and 2. 1M, 1RR, and 1SS show quasi identical plots, as does the pair of 2RR and 2SS isomers. Therefore, only one measurement for each family of enantiomers will be discussed. The roomtemperature cMT value for compound 1RR of $2.62 \mathrm{~cm} 3 \mathrm{~mol} @ 1 \mathrm{~K}$ is larger than the expected value for two isolated $\mathrm{S}=1$ centers $(2.0 \mathrm{~cm} 3 \mathrm{~mol} @ 1 \mathrm{~K}$ for $\mathrm{g}=2.00)$. Upon cooling, the cMT product increases gradually to $16 \mathrm{~K}(3.56 \mathrm{~cm} 3 \mathrm{~mol} @ 1 \mathrm{~K})$. Below this temperature, the cMT product decreases to 3.15 
$376 \mathrm{~cm} 3 \mathrm{~mol} @ 1 \mathrm{~K}$ at $2 \mathrm{~K}$ (Figure 14). Complex 2RR has a similar response, with a room-temperature cMT

377 value of $2.77 \mathrm{~cm} 3 \mathrm{~mol} @ 1 \mathrm{~K}$, a maximum value of $3.56 \mathrm{~cm} 3 \mathrm{~mol} @ 1 \mathrm{~K}$ at $20 \mathrm{~K}$ and a final value of 3.23

$378 \mathrm{~cm} 3 \mathrm{~mol} @ 1 \mathrm{~K}$ at $2 \mathrm{~K}$. The cMT plots evidence strong intramolecular ferromagnetic interactions between

379 the NiII centers. Considering that the structural data do not show relevant intercluster interactions, the

380 decay of cMT at low temperature should be attributed to D effects.

381 A fit of the experimental data was performed in the full range of temperature by using the PHI

382 program[56] based on the Hamiltonian $\mathrm{H}=@ 2 \mathrm{~J} 1(\mathrm{~S} 1 \cdot \mathrm{S} 2)$ and including a Dion term.

383 The best fit of the experimental data gave $\mathrm{J}=+14.9 \mathrm{~cm} @ 1, \mathrm{~g}=2.18$ and Dion=2.07 cm@1 for 1RR

$384(\mathrm{R}=8.1 \mathrm{~V} 10 @ 6)$, and J=+19.2 cm@1,g=2.23 and Dion=2.30 cm@1 for 2RR (

385 these $\mathrm{J}$ values it can be inferred that the ground state is a well isolated $\mathrm{S}=2$ level. The magnetization data

386 show quasisaturated values of 4.32 and $4.24 \mathrm{Nmb}$ for $1 \mathrm{RR}$ and $2 \mathrm{RR}$, respectively.

387 These results show good agreement with the expected magnetic response and the reported values for

388 [Ni2(L5)(N3)2](ClO4)2 and [Ni2(L5)(N3)2](ClO4)2.[40] 


\section{CONCLUSIONS}

391

392 A complete family of NiII dimers built from bis-bidentate Schiff bases with the general formula

393 [Ni2(L)2(N3)2]2+, showing the transition from mesocate to helicate conformation, has been structurally

394 characterized and related to the flexibility of the central spacer of the ligands and the size of the

395 substituents of the Schiff base (pyridy1/quinoxalyl). The ECD spectra in both the solid state and solution

396 have been measured for two pairs of enantiomers showing that the systems are stable in solution and

397 their spectra have been rationalized by DFT calculations. Notably, the unprecedented structure of

398 complex 7 shows simultaneous crystallization of both conformations in the same unit cell and enables

399 the characterization of the first coordination compound derived from the imine-quinoxalyl ligand L4.

400 
Physical measurements: Magnetic susceptibility measurements were carried out on polycrystalline samples with a MPMS5 Quantum Design susceptometer working in the range 30-300 K under magnetic fields of $0.3 \mathrm{~T}$ and under a field of $0.03 \mathrm{~T}$ in the $30-2 \mathrm{~K}$ range to avoid saturation effects at low temperature. Diamagnetic corrections were estimated from Pascal Tables. Infrared spectra (4000-400 cm@1) were recorded from KBr pellets with a Bruker IFS-125 FT-IR spectrophotometer. ECD spectra were recorded with a Jasco J-710 spectropolarimeter. Solution spectra were recorded in 2V10@4m $\mathrm{CH} 3 \mathrm{CN}$ solutions; solid-state spectra were recorded using the $\mathrm{KCl}$ pellet technique. To rule out the occurrence of contributions from linear dichroism/linear birefringence due to preferential orientation of the solid sample, the disc was rotated by 908, 1808, 2708 and then flipped around its C2 axis. A spectrum was recorded after each rotation to check that no significant difference depending on the rotation angle was present. VCD spectra were recorded with a Jasco FVS 6000 spectropolarimeter on

$414 \mathrm{KCl}$ discs. DFT calculations: Calculations were run with Gaussian09, rev. D01,[57] starting from the X-ray geometry of 1SS, which was fully re-optimized at B3LYP/6-31G(d) level to a true energy minimum (no imaginary frequencies). A structure with +2 charge and quintet spin state was used in all calculations. Excited states TDDFT calculations were run with several different functionals, including B3LYP, CAM-B3LYP, X3LYP, BH\&HLYP, PBE-1/3, and basis sets, including SVP, TZVP and LanL2DZ (with ECP for Ni), including up to 100 excited states (roots). Single-crystal X-ray structure analyses: Prism-like specimens of 1M, 1SS, 1RR, 2SS, 2RR, 4R, and 7 and multiple crystals of the complexes derived from L3 were used for the X-ray crystallographic analysis. The X-ray intensity data were measured with a D8-Venture system equipped with a multilayer monochromator and a Mo microfocus $(1=0.71073$ a). The frames were integrated with the Bruker SAINT software package using a narrow-frame algorithm. The final cell constants were based upon the refinement of the XYZ-centroids of reflections above $20 \mathrm{~s}(\mathrm{I})$. Data were corrected for absorption effects by using the multi-scan method (SADABS). The structures were solved using the Bruker SHELXTL Software Package, and refined using SHELXL.[58] Details of crystal data, collection and refinement are summarized in Tables S6-S9. Analyses of the structures and plots for publication were performed with Ortep3[59] and POVRAY programs.

\section{Syntheses}

Schiff bases L1 and L2 were isolated as solids, whereas L3, L4, and L7 were prepared in situ and the ligand solution was employed directly to synthesize the corresponding complexes. Rac-L1, RR-L1, and 
SS-L1. A solution of 2-pyridinecarboxaldehide $(3.9 \mathrm{mmol})$ and the corresponding diaminociclohexane isomer $(1.75 \mathrm{mmol})$ in methanol $(20 \mathrm{~mL})$ was stirred for $2 \mathrm{~h}$ at room temperature. Concentration in vacuo afforded ligands L1 as white solids that were recrystallized in diethyl ether. RR-L2 and SS-L2: A similar procedure was employed for RR-L2 and SS-L2. A solution of the corresponding isomer of 1,2-cyclohexanediamine $(0.5 \mathrm{mmol})$ and 2-quinolinecarboxaldehide $(1 \mathrm{mmol})$ were mixed in dichloromethane $(20 \mathrm{~mL})$ and stirred at room temperature for $24 \mathrm{~h}$. After concentration to one half volume, the solution was mixed with $\mathrm{n}$-hexane $(20 \mathrm{~mL})$. L2 was collected as a yellowish powder. Recrystallization in diethyl ether afforded the yellowish crystals used for syntheses. IR spectra are shown in Figure S4. [Ni2(L)2(N3)2](NO3)2 $\cdot \mathrm{nMeOH}(\mathrm{L}=\mathrm{L} 1,1 \mathrm{M} \cdot 2 \mathrm{MeOH}, 1 \mathrm{RR} \cdot 2 \mathrm{MeOH}, 1 \mathrm{SS} \cdot 2 \mathrm{MeOH} ; \mathrm{L}=\mathrm{L} 2$, $2 \mathrm{RR} \cdot 3 \mathrm{MeOH}, 2 \mathrm{SS} \cdot 3 \mathrm{MeOH})$ : The complexes were synthesized by following the same experimental procedure: The corresponding L1 or L2 ligand (1 mmol) and $\mathrm{Ni}(\mathrm{NO} 3) 2 \cdot 6 \mathrm{H} 2 \mathrm{O}(1 \mathrm{mmol})$ were solved in methanol $(20 \mathrm{~mL})$ and stirred for some minutes. To this solution was added sodium azide $(1 \mathrm{mmol})$ solved in methanol ( $5 \mathrm{~mL})$. Crystallization by vapor diffusion of diethyl ether afforded well-formed reddish crystals after one to two days. Anal. Calcd/found (\%) for 1M/1RR/1SS as C38H48N16Ni2O8: C, 46.85/46.8/464/46.5; H, 4.97/4.6/4.3/5.1; N, 23.00/22.9/23.2/23.4. Calc/found (\%) for 2RR/2SS as C55H60N16Ni2O9: C, 54.75/53.9/54.3/54.2; H, 5.01/4.8/4.7/5.2; N, 18.57/18.9/18.3/18.5. IR spectra are shown in Figure S4.

[Ni2(R-L4)2(N3)2] $(\mathrm{ClO} 4) 2 \cdot \mathrm{H} 2 \mathrm{O}(4 \mathrm{R} \cdot 0.25 \mathrm{H} 2 \mathrm{O})$ : Synthesized by preparing the ligand in situ by mixing R- or S-1,2-diaminopropane hydrochloride $(0.25 \mathrm{mmol})$ with triethilamine $(0.5 \mathrm{mmol})$ and quinoline carboxaldehyde $(0.5 \mathrm{mmol})$. The mixture was heated to reflux in $\mathrm{MeOH}$ for $1 \mathrm{~h}$. After cooling, $\mathrm{Ni}(\mathrm{ClO} 4) 2 \cdot 6 \mathrm{H} 2 \mathrm{O}(0.25 \mathrm{mmol})$ and $\mathrm{NaN} 3(0.25 \mathrm{mmol})$ were added. The mixture was stirred at room temperature for $30 \mathrm{~min}$ and filtered. Crystallization by vapor diffusion of diethyl ether produced wellformed reddish crystals after a few days. Anal. Calcd/found (\%) for 4R as C46H40.5Cl2N14Ni2O8.25: C, 49.79/49.3; H, 3.67/3.8; N, 17.67/17.4. IR spectra are shown in Figure S5. [Ni2(L3)2(N3)2](X)2 (3) (X=NO3 @, ClO4 @): The six complexes derived from L3 (meso, R and S) were synthesized in the search for adequate crystals to obtain structural inf ormation, but all data collection were unsuccessful. The syntheses were performed by following the same procedure employed for 4R. IR spectra are shown in Figure S6. $\mathrm{Ni} 2(\mathrm{~L} 7) 2(\mathrm{~N} 3) 2](\mathrm{NO} 3) 2 \cdot 2 \mathrm{H} 2 \mathrm{O} \cdot 2 \mathrm{MeOH}(7 \cdot 2 \mathrm{H} 2 \mathrm{O} \cdot 2 \mathrm{MeOH})$ : Prepared by synthesizing the ligand in situ by mixing ethylenediamine $(0.025 \mathrm{mmol})$ and quinoline carboxaldehide $(0.5 \mathrm{mmol})$ and heating to reflux for $1 \mathrm{~h}$. After cooling, $\mathrm{Ni}(\mathrm{NO} 3) 2 \cdot 6 \mathrm{H} 2 \mathrm{O}(0.25 \mathrm{mmol})$ and sodium azide $(0.25 \mathrm{mmol})$ were added and the mixture was stirred at room temperature $30 \mathrm{~min}$. The solution was filtered and layered with diethyl ether. Red crystals were obtained after a few days. Anal. Calcd/found (\%) for 7 as 


\section{ACKNOWLEDGEMENTS}

475

476 JM and AE thank the Ministerio de Economia y Competitividad (Project CTQ2015-63614-P) for 477 financial support.

478 
[1] O. Mamula, A. von Zelewsky, Coord. Chem. Rev. 2003, 242, 87-95.

482

A. Myari, N. Hadjiliadis, A. Garoufis, J. Inorg. Biochem. 2005, 99, 616-626.

485

[4] E. Francotte, W. Lindner, Chirality in Drug Research, Wiley-VCH, Weinheim, 2006.

486

[5]

K. Szacilowski, W. Mazyk, A. Drzewiecka-Matuszek, M. Brindell, G. Stochel, Chem. Rev.

[6] E. Yashima, N. Ousaka, D. Taura, K. Shimomura, T. Ikai, K. Maeda, Chem. Rev. 2016, 116, $13752-13990$

490

[7] Y. Inoue, V. Ramamurthy, Chiral Photochemistry, Marcel Dekker, New York 2004, pp. 261313.

492

[8] K. Mikami, M. Lantens, New Frontiers in Asymmetric Catalysis, Wiley, Hoboken, 2007.

R. Gjmez Array\#s, J. Adrio, J. C. Carretero, Angew. Chem. Int. Ed. 2006, 45, 7674-7715;

494 Angew. Chem. 2006, 118, 7836-7878.

495

[10] G. C. Fu, Acc. Chem. Res. 2006, 39, 853-860.

[11] T. Katsuki, Chem. Soc. Rev. 2004, 33, 437-444.

497

[12] G. Chelucci, R. P. Thummel, Chem. Rev. 2002, 102, 3129-3170.

498

[13] J. M. Lehn, Supramolecular Chemistry: Concepts and Perspectives, VCH, Weinheim, 1995.

B. W. Ding, R. Keese, H. Stoeckli-Evans, Angew. Chem. Int. Ed. 1999, 38, 375-376; Angew. Chem. 1999, 111, 387-388.

J. Xu, K. N. Raymond, Angew. Chem. Int. Ed. 2006, 45, 6480-6485; Angew. Chem. 2006, 118 , $6630-6635$. 
[18] M. A. Masood, E. J. Enemark, T. D. P. Stack, Angew. Chem. Int. Ed. 1998, 37, 928-932; Angew. Chem. 1998, 110, 973-977.

[19] V. Amendola, L. Fabbrizzi, L. Linati, C. Mangano, P. Pallavicini, V. Pedrazzini, M. Zema, Chem. Eur. J. 1999, 5, 3679-3688.

[20] V. Amendola, L. Fabbrizzi, C. Mangano, P. Pallavicini, E. Roboli, M. Zema, Inorg. Chem. 2000, 39, 5803-5806.

[21] P. K. Pal, S. Chowdhury, P. Purkayastha, D. A. Tocher, D. Datta, Inorg. Chem. Commun. 2000, $3,585-589$.

[22] V. Amendola, L. Fabbrizzi, L. Gianelli, C. Maggi, C. Mangano, P. Pallavicini, M. Zema, Inorg. Chem. 2001, 40, 3579-3587.

[23] R. Ziessel, P. Nguyen, L. Douce, M. Cesario, C. Estournes, Org. Lett. 2004, 6, 2865-2868.

[24] G. K. Patra, I. Goldberg, New J. Chem. 2003, 27, 1124-1131.

[25] N. C. Habermehl, P. M. Angus, N. L. Kilah, L. Noren, A. D. Rae, A. C. Willis, S. B. Wild, Inorg. Chem. 2006, 45, 1445-1462.

[26] A. Ouali, M. Taillefer, J. F. Spindler, A. Jutand, Organometallics 2007, 26, 65-74.

[27] P. Pallavicini, M. Boiocchi, G. Dacarro, C. Mangano, New J. Chem. 2007, 31, 927-935.

[28] V. Amendola, M. Boiocchi, V. Brega, L. Fabbrizzi, L. Mosca, Inorg. Chem 2010, 49, 997-1007.

[29] M. Boiocchi, V. Brega, C. Ciarrocchi, L. Fabbrizzi, P. Pallavicini, Inorg. Chem. 2013, 52, $10643-10652$.

[30] G. C. van Stein, G. van Koten, K. Vrieze, C. Brevard, A. L. Spek, J. Chem. Soc., Chem. Commun. 1980, 1016-1018.

[31] G. C. van Stein, G. van Koten, K. Vrieze, C. Brevard, A. L. Spek, J. Am. Chem. Soc. 1984, 106, $4486-4492$.

[32] P. K. Bowyer, K. A. Porter, A. D. Rae, A. C. Willis, S. B. Wild, Chem. Commun. 1998, 11531154 .

[33] V. Amendola, Y. D. Fernandez, C. Mangano, M. Montalti, P. Pallavicini, L. Prodi, N. Zaccheroni, M. Zema, Dalton Trans. 2003, 4340-4345. 
[34] A. D. Amirnasr, M. Khalaji, R. Welter, Anal. Sci. 2006, 22, x151-x152.

[35] E. C. Constable, G. Zhang, C. E. Housecroft, J. A. Zampese, CrystEng- Comm 2010, 12, 3724 3732 .

[36] E. C. Constable, G. Zhang, C. E. Housecroft, M. Neuburger, J. A. Zampese, Eur. J. Inorg. Chem. 2010, 2000-2011.

[37] E. C. Constable, G. Zhang, C. E. Housecroft, J. A. Zampese, Dalton Trans. 2010, 39, 5332 5340 .

[38] T. Takeda, S. Harada, A. Nishida, Org. Lett. 2015, 17, 5184-5187.

[39] Y. I. Cho, D. M. Joseph, M. J. Rose, Inorg. Chem. 2013, 52, 13298-13300.

[40] M. Habib, T. K. Karmakar, G. Aromi, J. Ribas-Arino, H.-K. Fun, S. Chantrapromma, S. K. Chandra, Inorg. Chem. 2008, 47, 4109-4117.

[41] J. Crassous, Chem. Soc. Rev. 2009, 38, 830-845.

[42] M. Liu, L. Zhang, T. Wang, Chem. Rev. 2015, 115, 7304-7397.

[43] A. Frontera, P. Gamez, M. Mascal, T. J. Mooibroek, J. Reedijk, Angew. Chem. Int. Ed. 2011, 50, 9564-9583; Angew. Chem. 2011, 123, 9736-9756.

[44] M. Nishio, CrystEngComm 2004, 6, 130-158.

[45] R. Berardozzi, E. Badetti, N. A. Carmo dos Santos, K. Wurst, G. Licini, G. Pescitelli, C. Zonta, L. Di Bari, Chem. Commun. 2016, 52, 8428-8431.

[46] S. R. Domingos, H. J. Sanders, F. Hartl, W. J. Buma, S. Woutersen, Angew Chem. Int. Ed. 2014, 53, 14042-14045; Angew. Chem. 2014, 126, 14266 -14269.

[47] L. A. Nafie, J. Phys. Chem. A 2004, 108, 7222-7231.

[48] G. Pescitelli, T. Kurt\#n, U. Flçrke, K. Krohn, Chirality 2009, 21, E181 -E201.

[49] D. Padula, S. Di Pietro, M. A. M. Capozzi, C. Cardellicchio, G. Pescitelli, Chirality 2014, 26, $462-470$.

[50] M. Srebro-Hooper, J. Autschbach, Annu. Rev. Phys. Chem. 2017, 68, 399 -420.

[51] A. Ipatov, F. Cordova, L. J. Doriol, M. E. Casida, J. Mol. Struct. 2009, 914, 60-73. 
[52] M. Enamullah, M. A. Quddus, M. R. Hasan, G. Pescitelli, R. Berardozzi, G. Makhloufi, V. Vasylyeva, C. Janiak, Dalton Trans. 2016, 45, 667-680.

[53] M. E. Casida, C. Jamorski, K. C. Casida, D. R. Salahub, J. Chem. Phys. 1998, 108, 4439-4449.

[54] A. Letzen, M. Hapke, J. Griep-Raming, D. Haase, W. Saak, Angew. Chem. Int. Ed. 2002, 41, 2086-2089; Angew. Chem. 2002, 114, 2190-2194.

[55] A. Escuer, J. Esteban, S. P. Perlepes, T. C. Stamatatos, Coord. Chem. Rev. 2014, 275, 87-129.

[56] N. F. Chilton, R. P. Anderson, L. D. Turner, A. Soncini, K. S. Murray, J. Comput. Chem. 2013, $34,1164-1165$.

[57] Gaussian 09, Revision D.01, M. J. Frisch, G. W. Trucks, H. B. Schlegel, G. E. Scuseria, M. A. Robb, J. R. Cheeseman, G. Scalmani, V. Barone, B. Mennucci, G. A. Petersson, H. Nakatsuji, M. Caricato, X. Li, H. P. Hratchian, A. F. Izmaylov, J. Bloino, G. Zheng, J. L. Sonnenberg, M. Hada, M. Ehara, K. Toyota, R. Fukuda, J. Hasegawa, M. Ishida, T. Nakajima, Y. Honda, O. Kitao, H. Nakai, T. Vreven, J. A. Montgomery, Jr., J. E. Peralta, F. Ogliaro, M. Bearpark, J. J. Heyd, E. Brothers, K. N. Kudin, V. N. Staroverov, R. Kobayashi, J. Normand, K. Raghavachari, A. Rendell, J. C. Burant, S. S. Iyengar, J. Tomasi, M. Cossi, N. Rega, J. M. Millam, M. Klene, J. E. Knox, J. B. Cross, V. Bakken, C. Adamo, J. Jaramillo, R. Gomperts, R. E. Stratmann, O. Yazyev, A. J. Austin, R. Cammi, C. Pomelli, J. W. Ochterski, R. L. Martin, K. Morokuma, V. G. Zakrzewski, G. A. Voth, P. Salvador, J. J. Dannenberg, S. Dapprich, A. D. Daniels, :. Farkas, J. B. Foresman, J. V. Ortiz, J. Cioslowski, D. J. Fox, Gaussian, Inc., Wallingford CT, 2009.

[58] G. M. Sheldrick, Acta Crystallogr. Sect. A 2008, 64, 112-122. 
Scheme 1 a) Double helicate with bis-bidentate ligands around tetrahedral cations; b) bis-tridentate

ligands around octahedral cations; c) bis-bidentate ligands around octahedral cations and a bidentate coligand, and d) bis-bidentate ligands and two bridging co-ligands around octahedral cations.

585

Scheme 2 Ligands employed (L1, L2, L3, L4, L7) or referenced (L5, L6) in the present work. Asterisks denote the chiral C-atoms for ligands L1 to L4.

Figure. 1 Partially labeled view of the mesocate cationic dinuclear complex 1M. Color key for all 590 figures: NiII, green; $\mathrm{N}$, navy blue; $\mathrm{C}$, dark grey.

591

592

Figure.2 Partially labeled plot of complex 1RR. Atom labels are common for 1RR and 1SS.

593

Figure.3 Partially labeled plot of complex 2SS, common with 2RR.

595

Figure.4. Partially labeled plot of complex 4R.

Figure.5 Partially labeled plot of the helicate 7A (left) and the mesocate 7B (right) complexes.

599

600

Figure 6 (Top) Intermolecular interactions found in compounds 2RR and 2SS. p-p stacking is indicated 601 as blue dotted lines between centroids and Hring contacts as red dotted lines. (Bottom) Lateral view of 602 the $1 \mathrm{D}$ arrangement of the dimers.

603

604

605

Figure.7 (Top) Intermolecular interactions found in compound 4R. p-p stacking is indicated as blue dotted lines between centroids and O-ring contacts as red dotted lines. (Bottom) Lateral view of the 1D arrangement of dimers.

Figure 8 (Top) Intermolecular interactions found in compound 7A-L and 7A-D. CH $\cdots p$ ring contacts are indicated as red dotted lines. (Bottom, left) One layer of chains of D and L dimers between layers of parallel chains of mesocates. (Bottom, right) A lateral view of the parallel D and L chains of helical dimers.

Figure.9 (Top) Solid-state ECD spectra recorded for the 1RR (green line) and 1SS (red line) enantiomers. The spectra were recorded on $\mathrm{KCl}$ pellets. (Bottom) Normalized solution ECD spectra in 
$615 \mathrm{CH} 3 \mathrm{CN}$ recorded for $1 \mathrm{RR}$ and $1 \mathrm{SS}$ enantiomers. The spectra were recorded using a $0.1 \mathrm{~cm}$ cell for the $616200-380 \mathrm{~nm}$ region and a $1 \mathrm{~cm}$ cell for the $380-900 \mathrm{~nm}$ region.

618 Figure.10 (Top) Solid-state ECD spectra recorded for the two 2RR (green line) and 2SS (red line) 619 enantiomers. The spectra were recorded on $\mathrm{KCl}$ pellets. (Bottom) Normalized solution ECD spectra in $620 \mathrm{CH} 3 \mathrm{CN}$ recorded for $2 \mathrm{RR}$ and $2 \mathrm{SS}$ enantiomers. The spectra were recorded using a $0.1 \mathrm{~cm}$ cell for the 200-380 $\mathrm{nm}$ region and a $1 \mathrm{~cm}$ cell for the $380-900 \mathrm{~nm}$ region

622

623 Figure.11 Comparison between solid state (blue lines) and solution (black lines) ECD spectra for 1RR 624 and 1SS (top) and for 2RR and 2SS (bottom). RR enantiomers, continuous lines; SS enantiomers, dotted 625 lines.

626

627

Figure.12 TDDFT calculated absorption (top) and ECD (bottom) spectra for compound 1SS at CAMB3LYP/LanL2DZ level. Vertical bars represent calculated transitions with respective rotational and oscillator strengths. Spectra were plotted as sums of Gaussian with exponential band-width of $0.3 \mathrm{eV}$.

Figure.13 Main axial symmetry for triple M2L3 (lower NCCN torsion) and ML2X2 double helicates (larger NCCN torsion

Scheme 3 Helicate to mesocate transition as function of the spacer and ring size of the Schiff bases.

636 Figure.14 Plot of the cMT product versus $\mathrm{T}$ for compounds 1RR (circles) and 2RR (squares). Inset, magnetization plots. Solid lines show the best fits of the experimental data. 
640

641

642

643

644
SCHEME 1

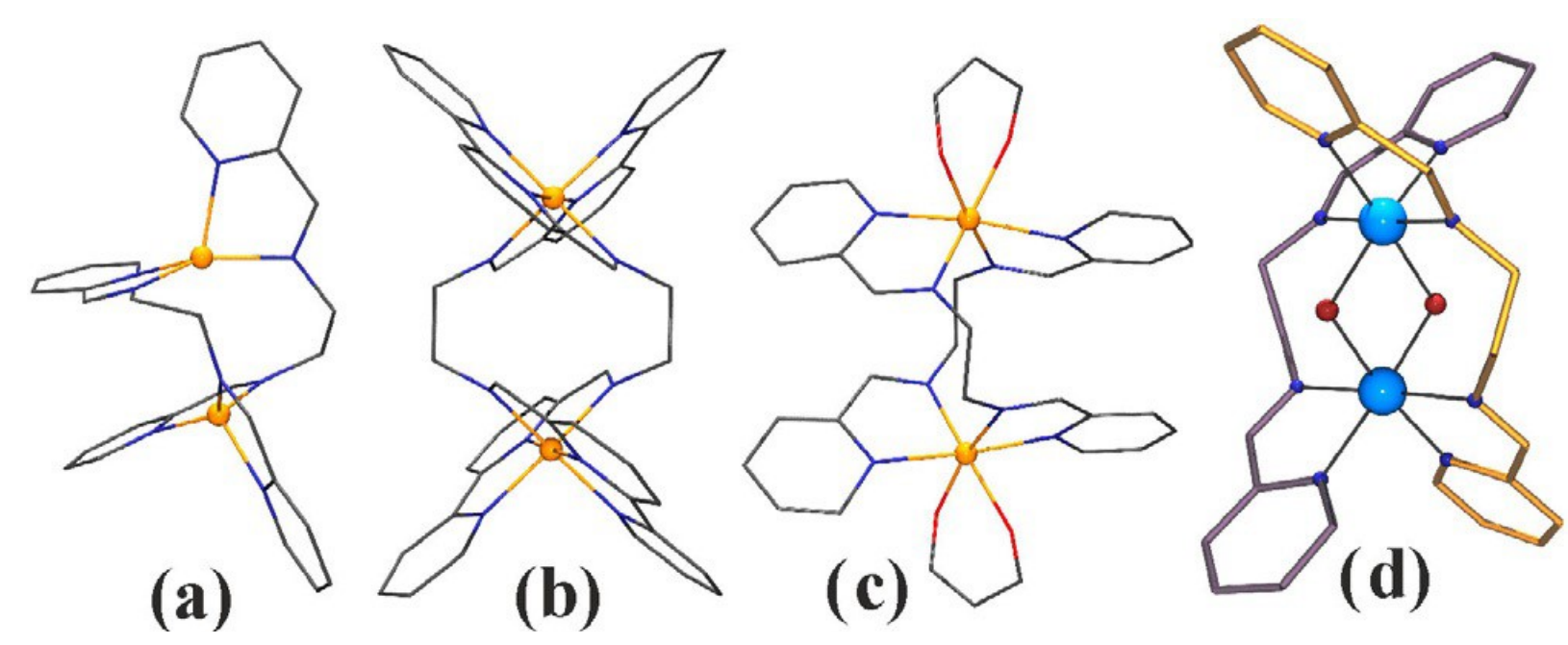


<smiles>CC(CN=Cc1ccccn1)N=Cc1ccccn1</smiles><smiles>CC(C)/N=C/c1ccc2ccccc2n1</smiles>

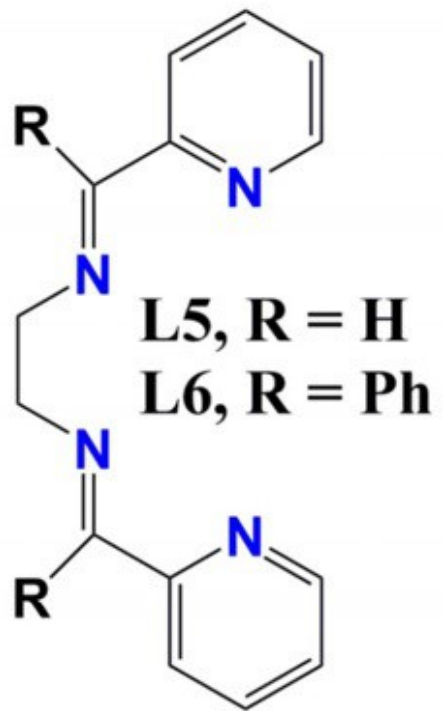<smiles>CC=Cc1ccc2ccccc2n1</smiles>

649 


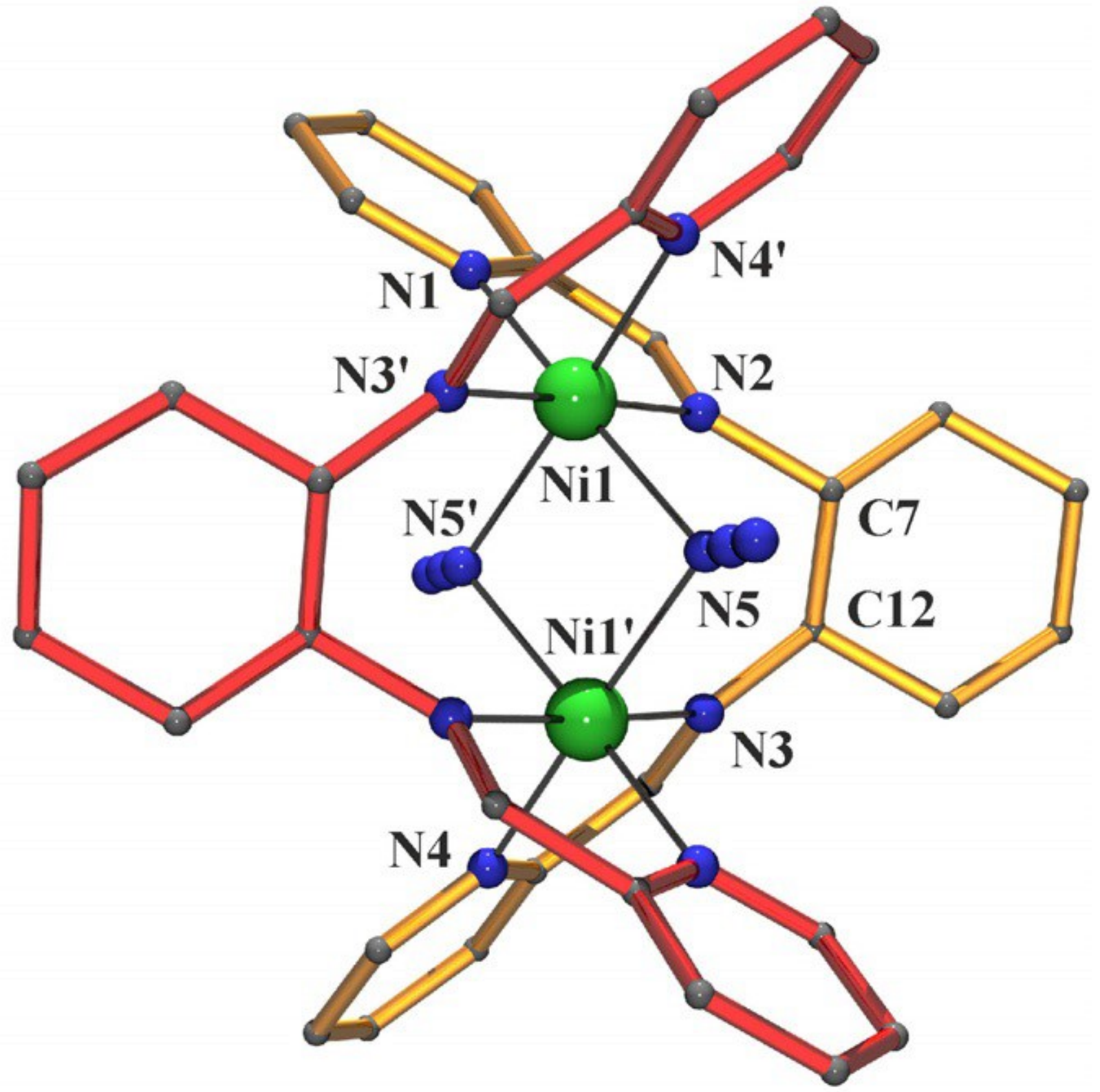

653

654

655

656 
659

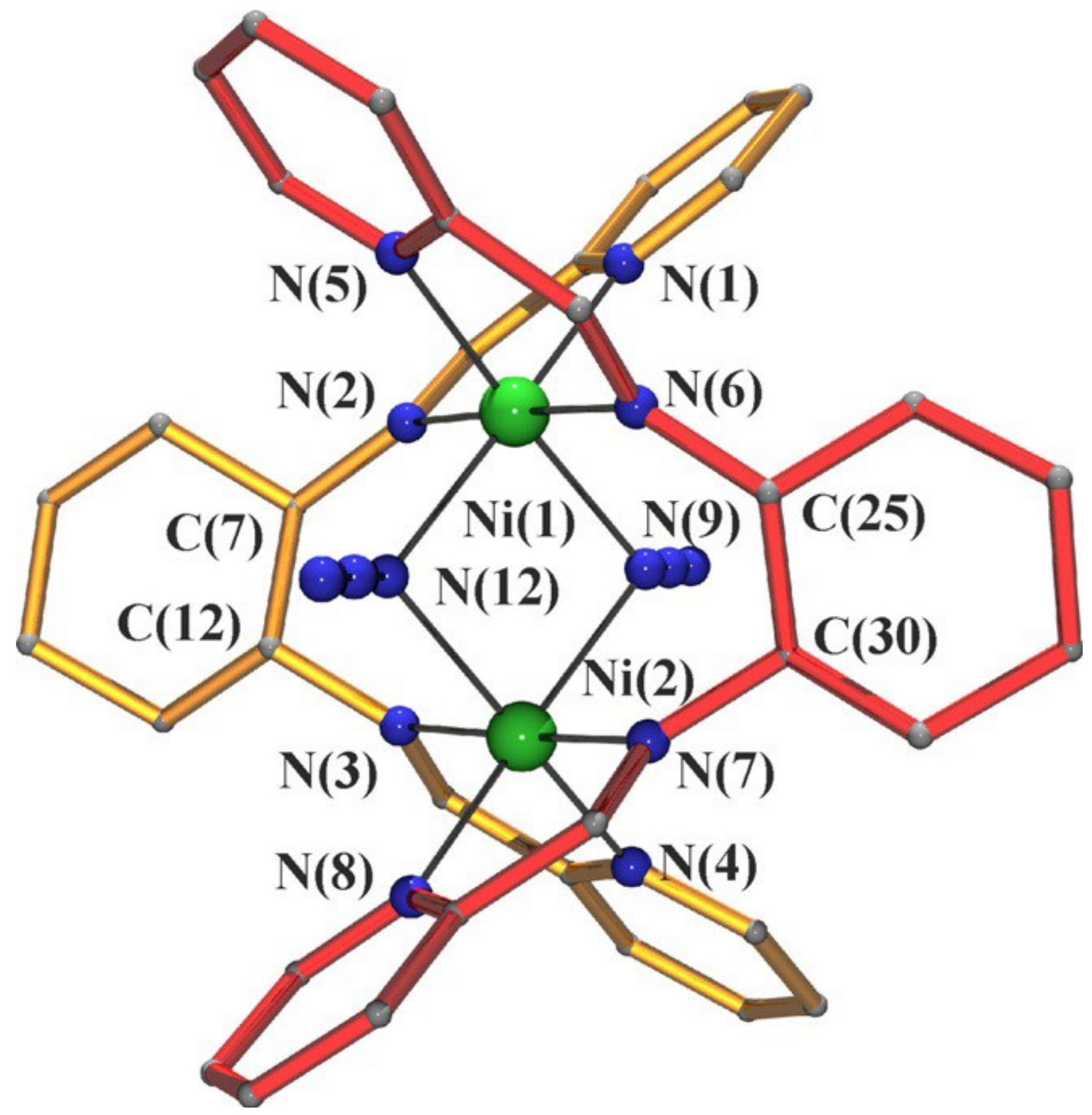




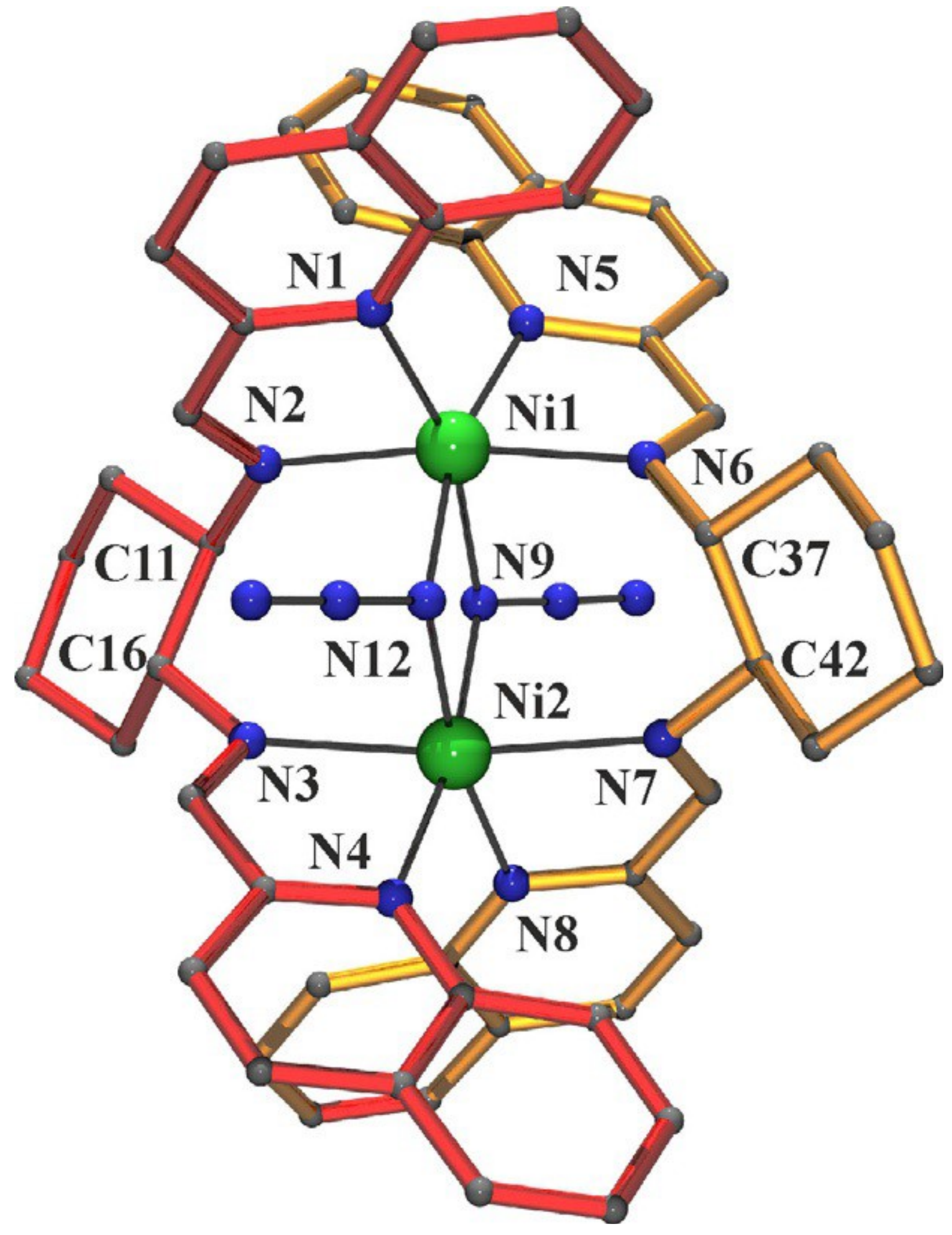




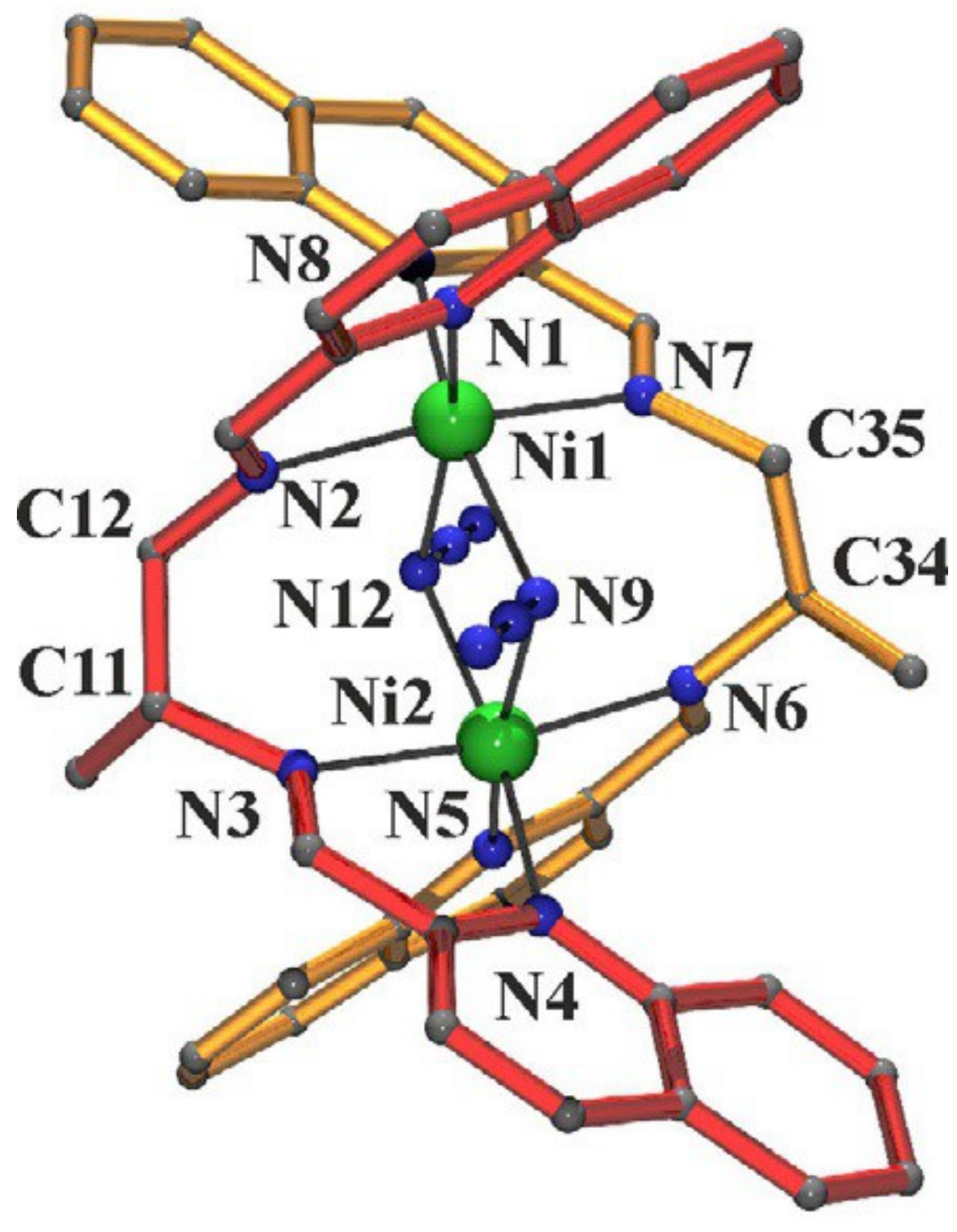



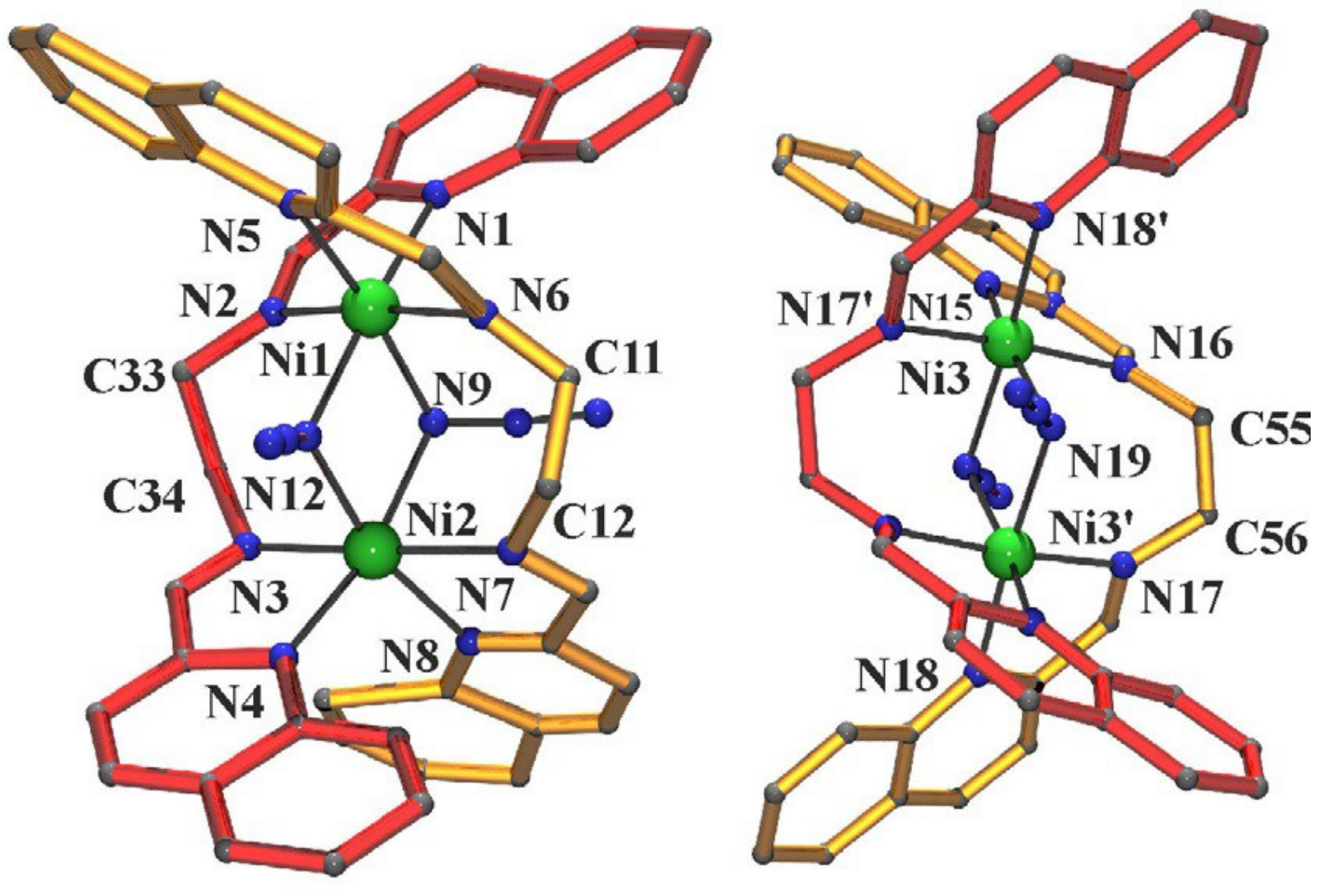

676 
677

FIGURE 6

678

679
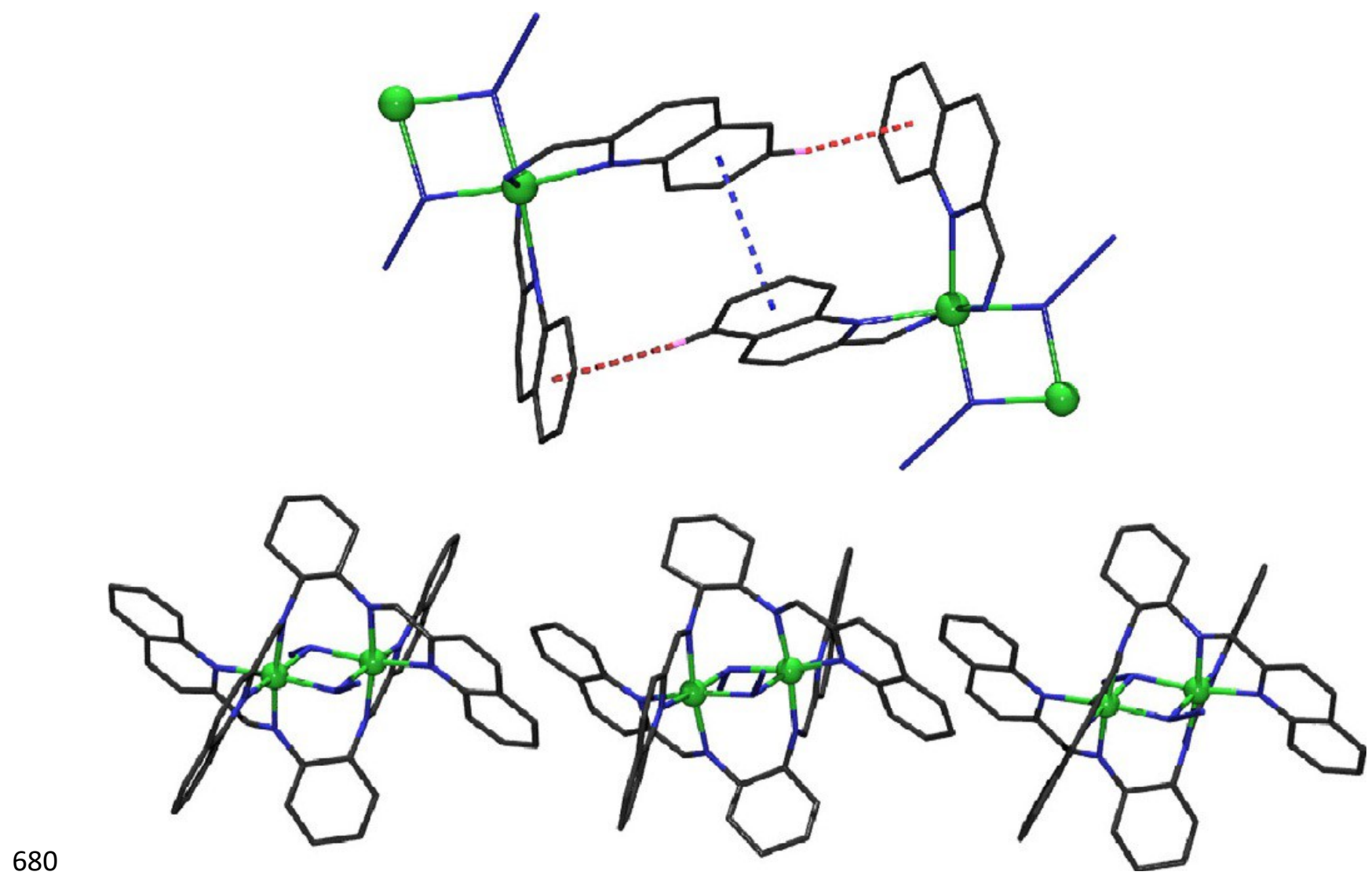

681 


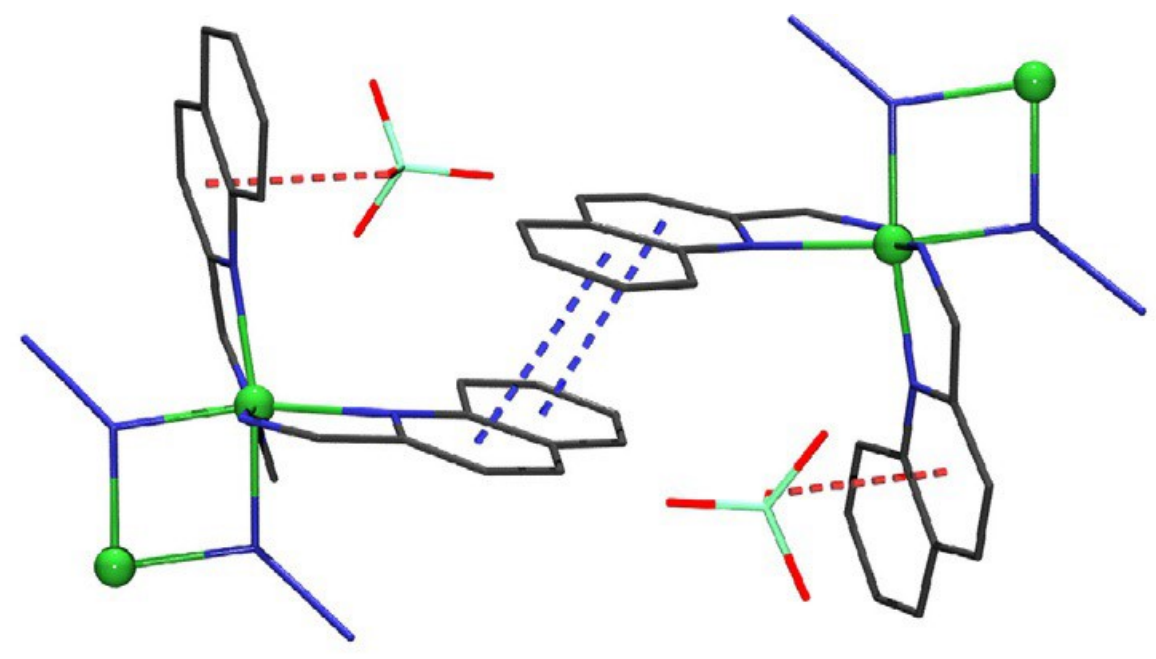

684

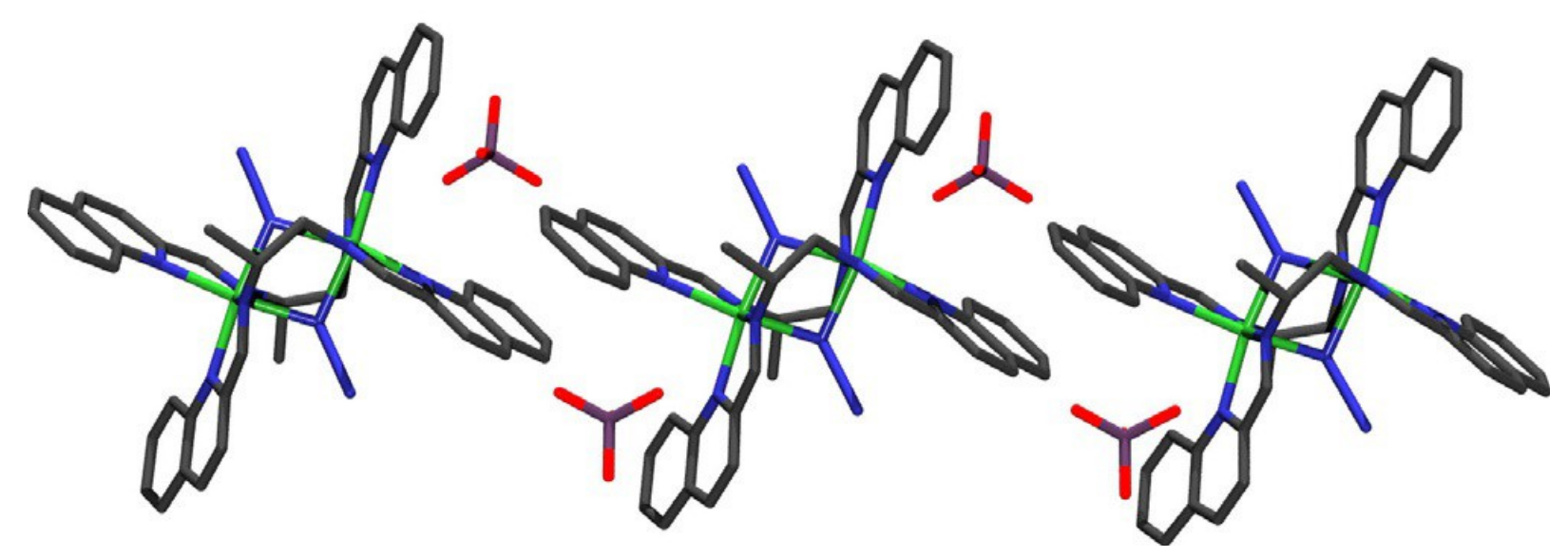




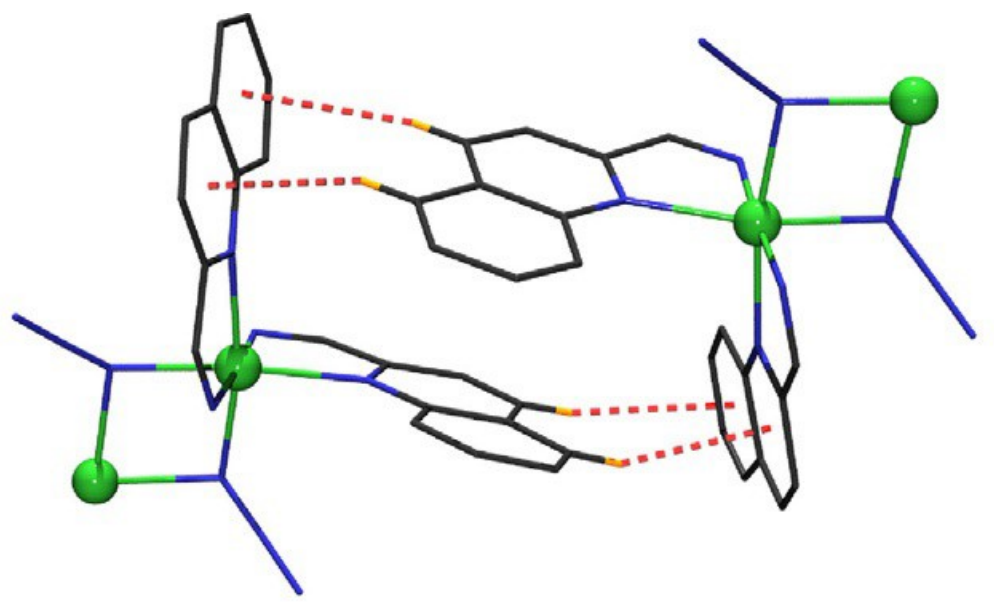

689

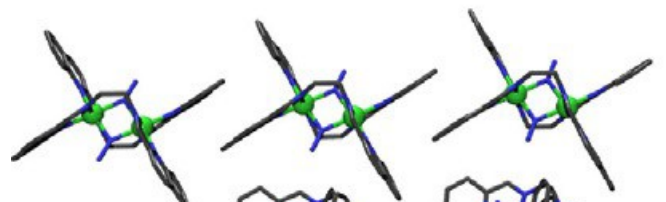
$\triangle$ or
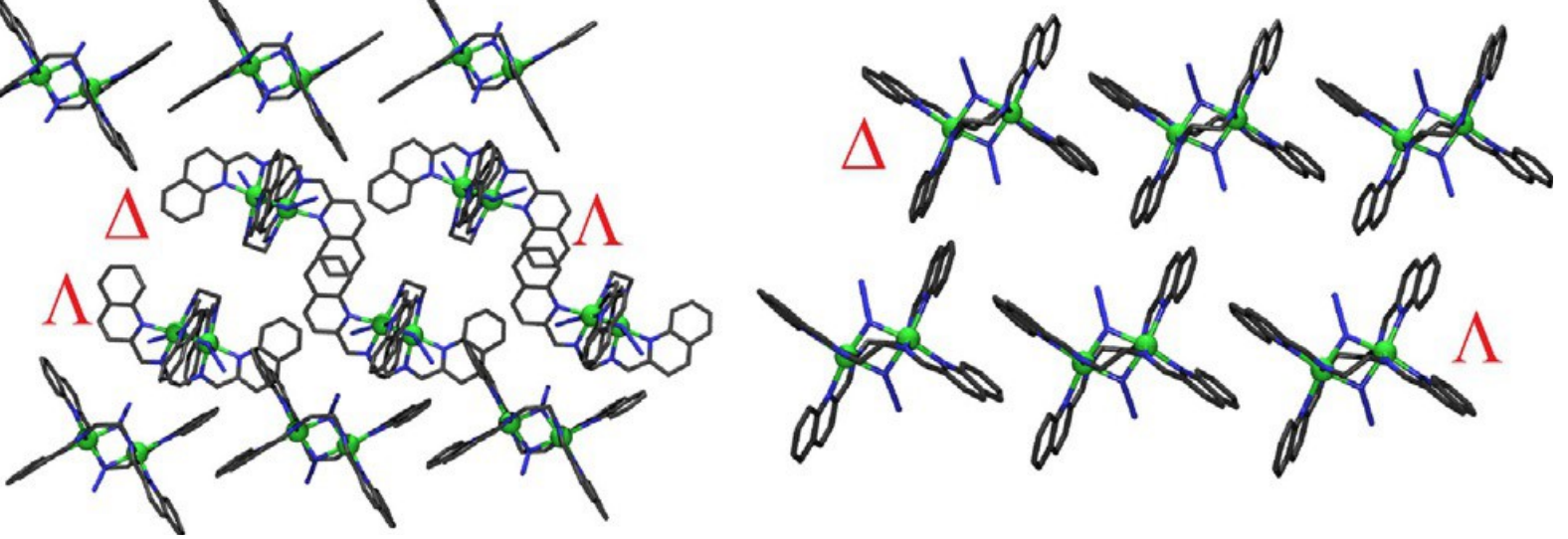

690 

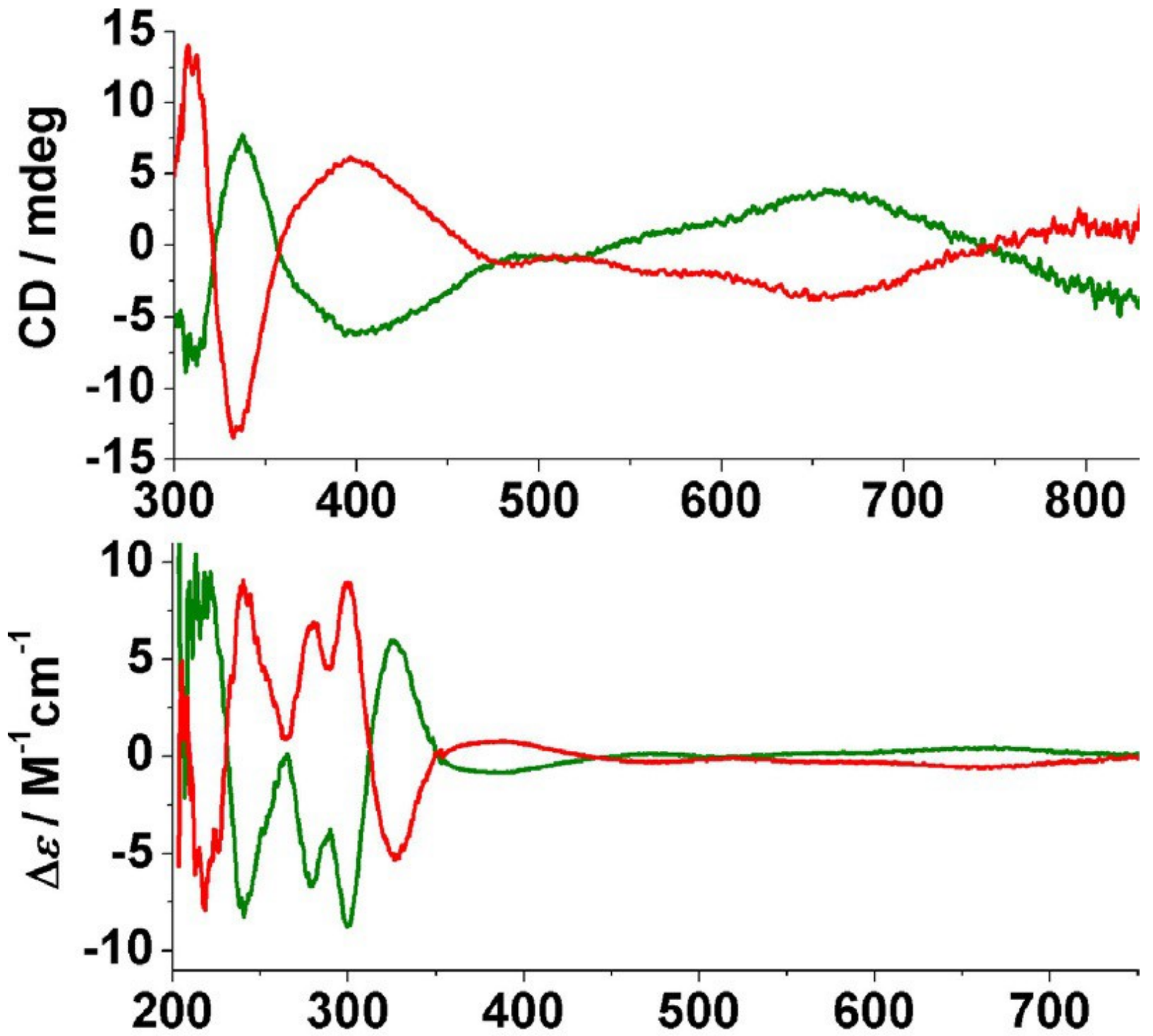

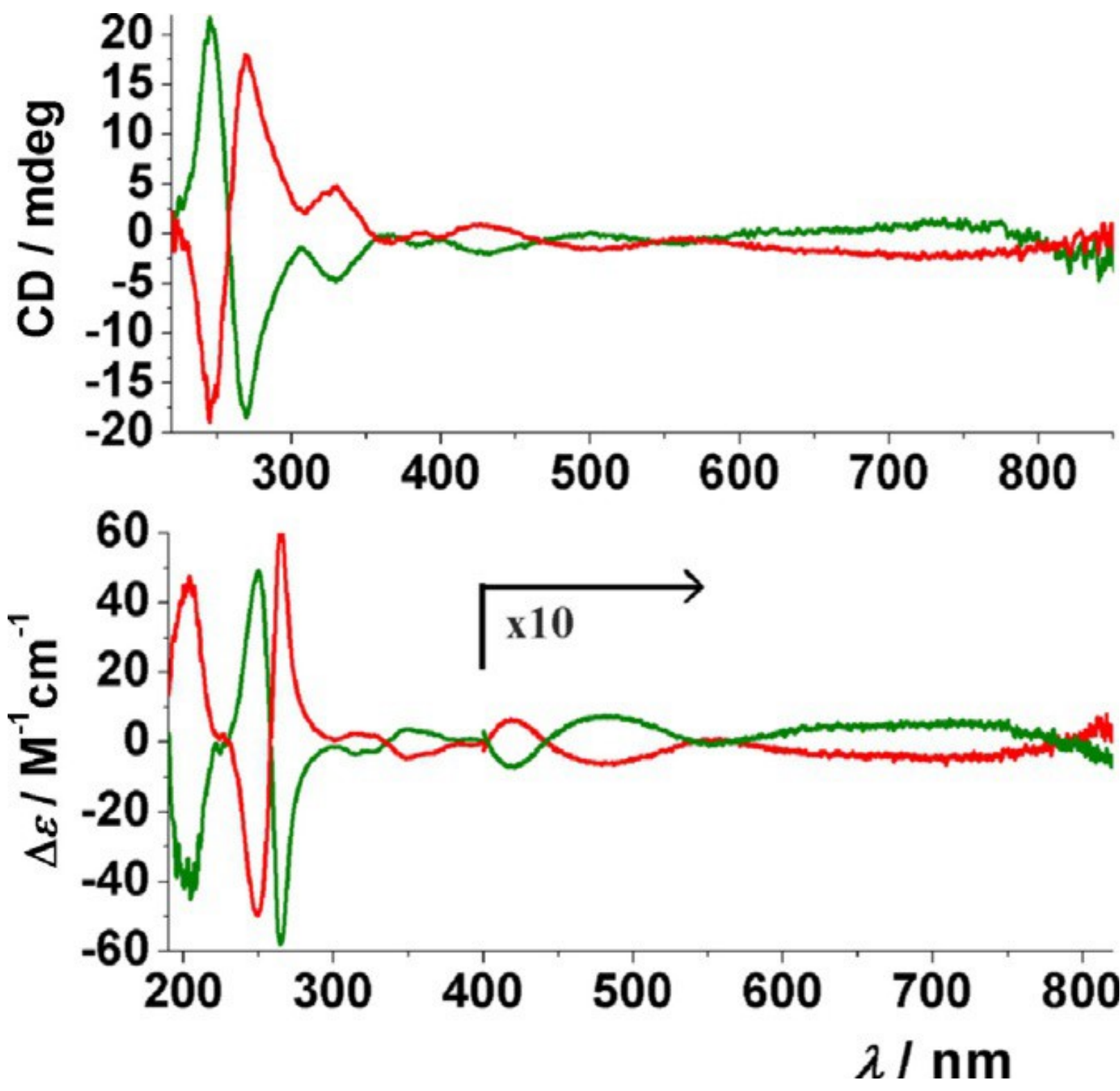

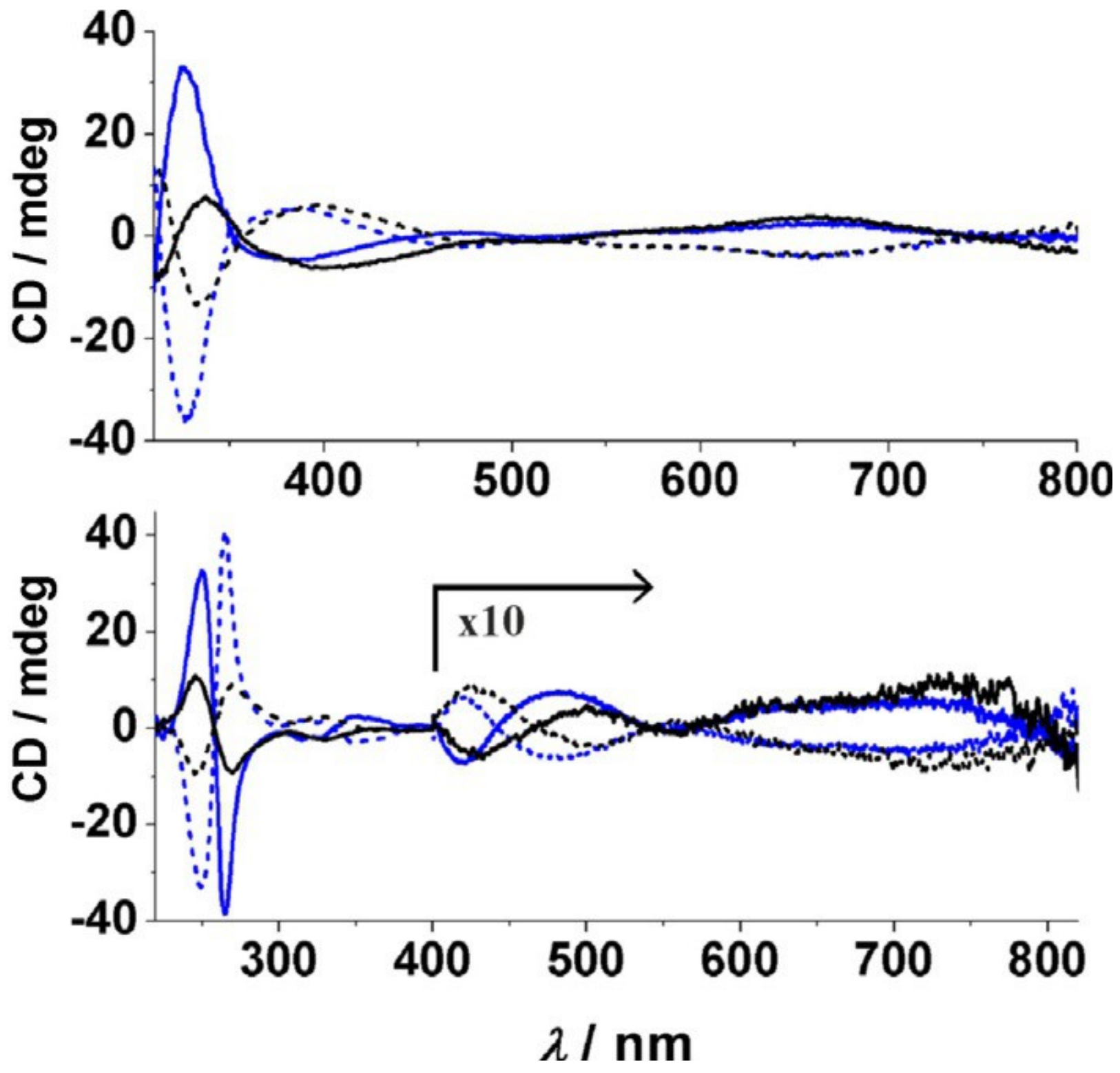
709
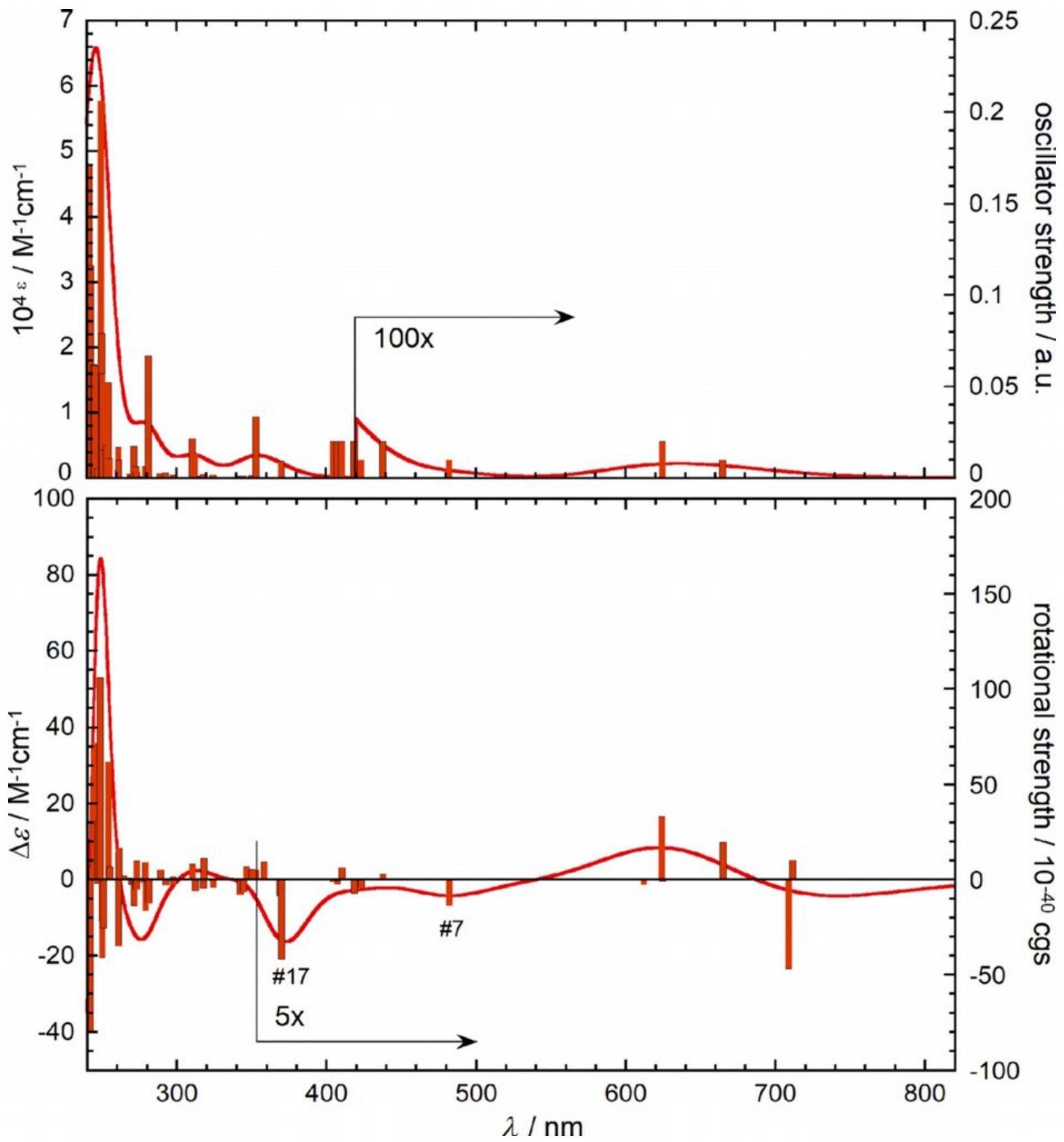
FIGURE.13

713

714
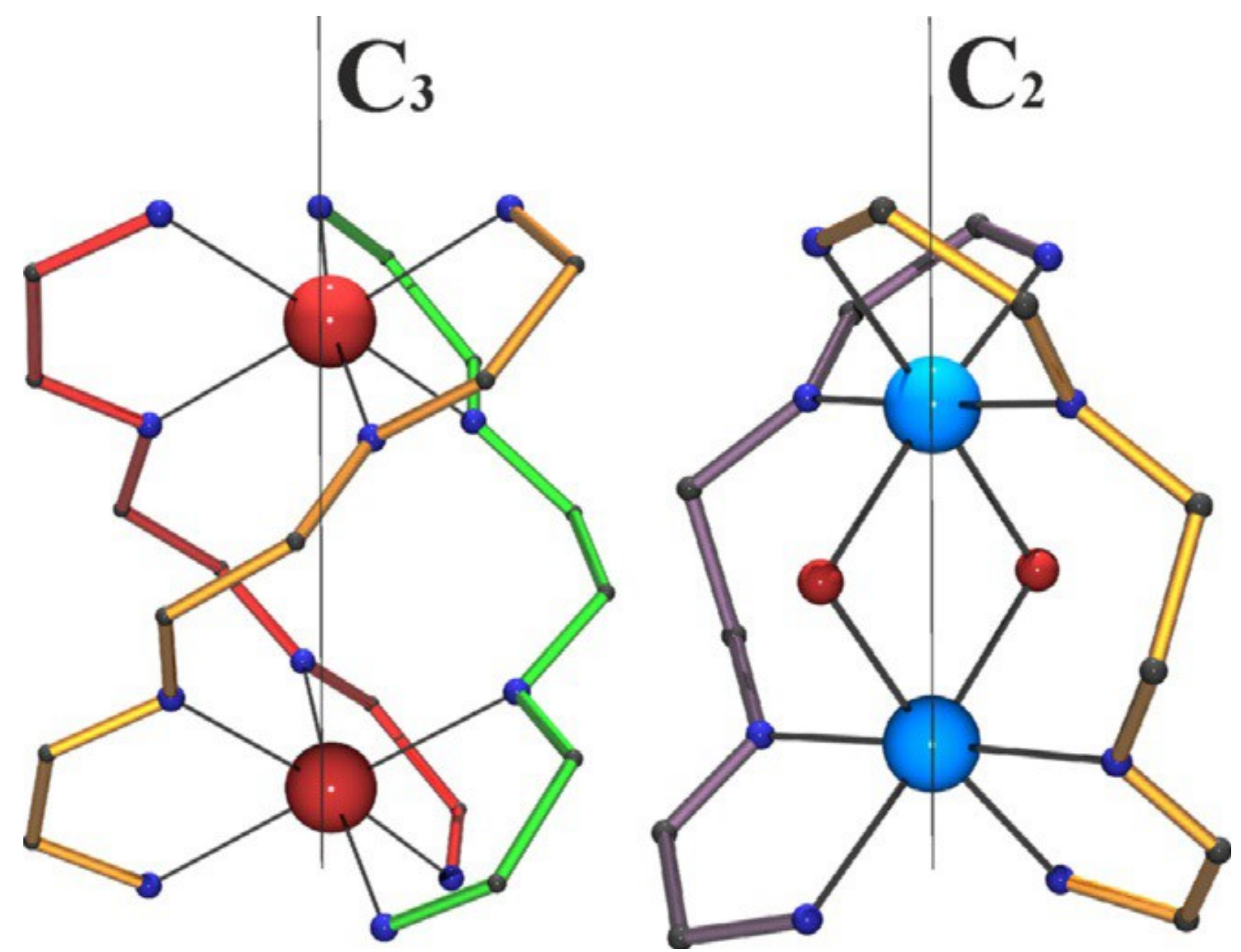

716 
717

718

719

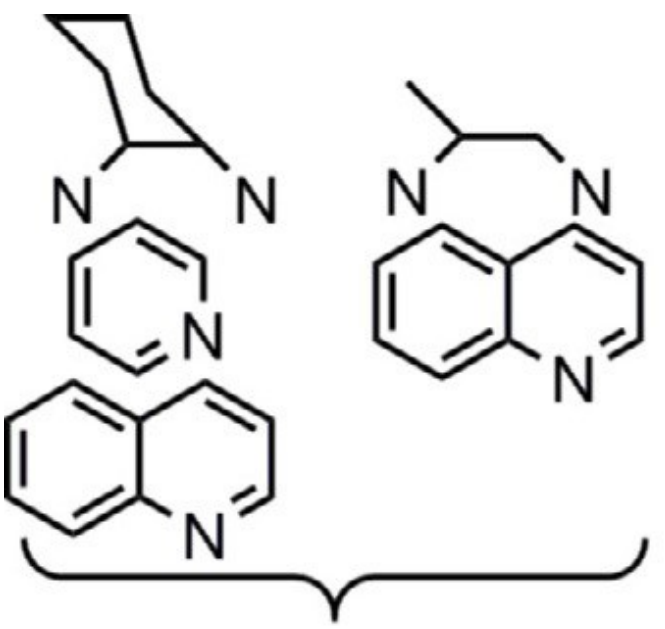

720

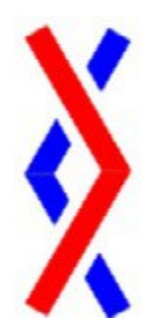

SCHEME 3<smiles>CC(N)CN</smiles><smiles>NCCN</smiles><smiles>NCCN</smiles><smiles>c1ccncc1</smiles><smiles>c1ccc2ncccc2c1</smiles><smiles>c1ccncc1</smiles>

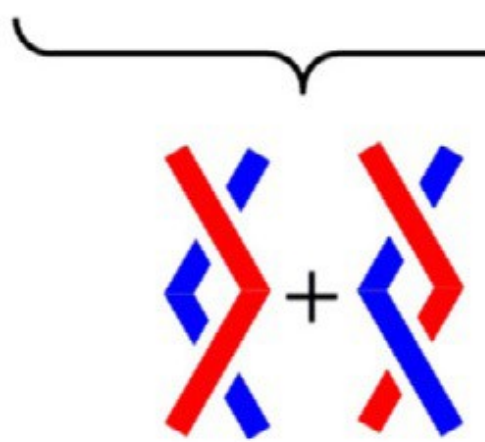

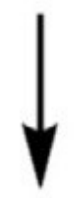

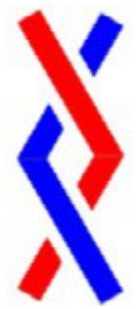

721 


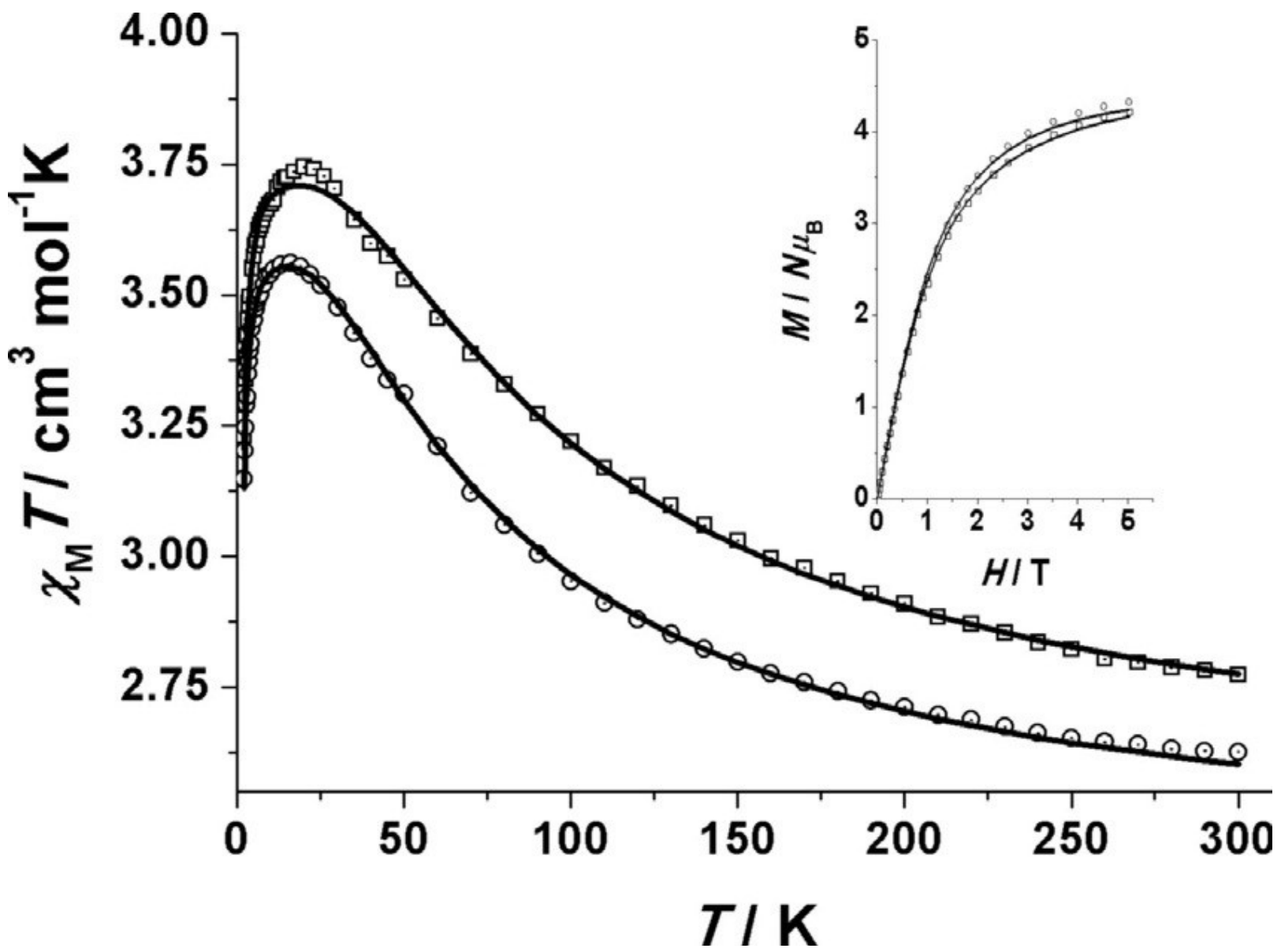

726 
729 Table 1. Selected bond lengths $[\AA]$ for compounds 1-7.

730

\begin{tabular}{|c|c|c|c|c|c|c|c|}
\hline & 1 & 2 & 3 & $4 \sqrt{2 \times 1}$ & 5 & 6 & 7 \\
\hline Ln1-01 & $2.3916(14)$ & $2.3698(1)$ & $2.3573(1)$ & $2.337(3)$ & $2.3283(2)$ & $23053(12)$ & $2262(2)$ \\
\hline $\ln 1-03$ & $24140(15)$ & $2.3705(1)$ & $23588\{1\}$ & $2340(3)$ & $2.3265(2)$ & $23008(13)$ & $2.409(2)$ \\
\hline $\ln 1-04$ & 2.4597(15) & $2.4066(1)$ & $23932\{1\}$ & $2.374(3)$ & $2.3567(2)$ & $23301(13)$ & $2.376(2)$ \\
\hline $\ln 1-05$ & $2.5671(15)$ & $2.5329(1)$ & 25259:1) & $2514(4)$ & $2.5056(2)$ & $24923(13)$ & $2.339(3)$ \\
\hline $\ln 1-06$ & $2.5089(16)$ & $2.4604(1)$ & $24478\{1\}$ & $2.423(4)$ & $24152(2)$ & 23853 (12) & $2.380(3)$ \\
\hline Ln1-N1 & $26249(16)$ & $2.5811(1)$ & $25711(1)$ & $2.572(4)$ & $2.5457(2)$ & 2520813) & $2.459(3)$ \\
\hline $\operatorname{Ln} 1-N 2$ & $26519(17)$ & $2.6170(1)$ & $26094(1)$ & $2608(5)$ & $2.5862(2)$ & $2.5659(15)$ & $2.385(6)$ \\
\hline $\ln 1-02^{\prime}$ & $24151(14)$ & $2.3531(1)$ & $23398(1)$ & $2.327(3)$ & $2.3120(2)$ & $22888(12)$ & $2206(2)$ \\
\hline $\ln 1-03^{\prime}$ & $2.7052(14)$ & $2.6969(1)$ & $26971(1)$ & 275107 & $2.7326(2)$ & $27432(12)$ & - \\
\hline $\ln 1 \cdots \operatorname{Ln} 1^{\prime}$ & $4.0015(4)$ & $3.9605(1)$ & $3.9517(3)$ & $3.9713(8)$ & $3.9497(4)$ & $39294(3)$ & $5.1519(7)$ \\
\hline Symmetry & $1-x, 1-y, 1-z$ & $1-x, 2-y_{0}-z$ & $-x, 2-x, 1-z$ & $-x,-x,-z$ & $1-x_{2} 1-y_{1} 1-z$ & $1-x, 1-y, 1-z$ & $1-x_{v} 1-y_{,} 2-z$ \\
\hline
\end{tabular}

731

732 
733 Table 2 Crystal data and collection details for the X-ray diffraction structure of complexes 1-3 and 5-7. 734

\begin{tabular}{|c|c|c|c|c|c|c|}
\hline & 1 & 2 & 3 & 5 & 6 & 7 \\
\hline \multirow{2}{*}{$\begin{array}{l}\text { Formula } \\
\text { Formula mass [g mol' } \\
\text { ग] }\end{array}$} & \multirow{2}{*}{$\begin{array}{l}\mathrm{C}_{52} \mathrm{H}_{22} \mathrm{~F}_{4} \mathrm{~N}_{6} \mathrm{Nd}_{2} \mathrm{O}_{14} \\
132932\end{array}$} & $\mathrm{C}_{52} \mathrm{H}_{42} \mathrm{Eu}_{2} \mathrm{~F}_{4} \mathrm{~N}_{6} \mathrm{O}_{14}$ & $\mathrm{C}_{52} \mathrm{H}_{22} \mathrm{Gd}_{2} \mathrm{~F}_{4} \mathrm{~N}_{6} \mathrm{O}_{14}$ & $\mathrm{C}_{62} \mathrm{H}_{42} \mathrm{D}_{4} \mathrm{~F}_{4} \mathrm{~N}_{6} \mathrm{O}_{14}$ & $\mathrm{C}_{62} \mathrm{H}_{22} \mathrm{Er}_{2} \mathrm{~F}_{4} \mathrm{~N}_{6} \mathrm{O}_{14}$ & $\mathrm{C}_{62} \mathrm{H}_{40} \mathrm{~F}_{6} \mathrm{~N}_{4} \mathrm{O}_{12} \mathrm{Yb}_{2}$ \\
\hline & & 134476 & 135534 & 1365.84 & 1375.36 & 1541.10 \\
\hline System & triclinic & triclinic & triclinic & triclinic & triclinic & triclinic \\
\hline Space group & PI & PI & PI & pl & PI & PI \\
\hline$a$ [ذ] & $106739(7)$ & $106539(2)$ & $10.6487(3)$ & $106699(7)$ & $10.6433(4)$ & $11.5251(15)$ \\
\hline$b[\dot{\mathrm{k}}]$ & $10.7928(7)$ & $10.8226(3)$ & $10.8322(3)$ & $10.8859(7)$ & $10.8789(4)$ & $11.6743(11)$ \\
\hline$c[$ [A] & $11.2992(7)$ & $11.1880(3)$ & $11.1560(3)$ & $11.1024(7)$ & $11.0468(4)$ & $11.9243(11)$ \\
\hline$a[]$ & $83332(2)$ & $83.521(2)$ & $83.599(2)$ & $83.870(2)$ & $83.902(1)$ & $114.216(8)$ \\
\hline$\beta[]$ & $82070(2)$ & $81.661(2)$ & $81.561(2)$ & $81.282(2)$ & $81.129(1)$ & $99.451(5)$ \\
\hline$y[]$ & $70223(2)$ & $70001(2)$ & $69.942(2)$ & $69.645(2)$ & $69.463(1)$ & $92.998(5)$ \\
\hline$V\left[A^{3}\right]$ & $1209.82(14)$ & $1196.63 / 5]$ & $1193.10(6)$ & $1193.03 / 13)$ & $1181.58(8)$ & $1430.5(3)$ \\
\hline$Z$ & 1 & 1 & 1 & 1 & 1 & 1 \\
\hline$T[\mathrm{~K}]$ & $100[2]$ & $100,2]$ & $100(2)$ & $100(2)$ & $100(2)$ & $100(2)$ \\
\hline $2\left(\mathrm{Mo}_{\mathrm{O}}-\mathrm{K}_{2}\right)[\overline{\mathrm{A}}]$ & 0.71073 & 0.71073 & 0.71073 & Q.71073 & 0.71073 & 0.71073 \\
\hline$D_{\text {eak }}\left[\mathrm{g} \mathrm{cm}^{-2}\right]$ & 1.825 & 1.866 & 1.886 & 1.901 & 1.933 & 1.789 \\
\hline$\mu\left(\mathrm{Mo}_{0}-\mathrm{K}_{2}\right]\left[\mathrm{mm}^{-1}\right]$ & 2.215 & 2.691 & 2.849 & 3.202 & 3.622 & 3.339 \\
\hline $\mathrm{R}$ & $0.0568(7009)$ & $0.0237(6769)$ & 0.0152 (13966) & $0.0254(7176)$ & 0.0151 (6938) & $0.0337(7481)$ \\
\hline$w P_{2}$ & 0.0206 (7260) & $0.0562(7278)$ & $0.0353(15022)$ & $0.0643(7312)$ & $0.0384(7208)$ & 0.0709 (88878) \\
\hline
\end{tabular}

